\title{
Regioselective synthesis, isomerisation, in vitro oestrogenic activity, and copolymerisation of bisguaiacol $F$ (BGF) isomers $\uparrow$
}

\author{
Steven-Friso Koelewijn, (D) *a Dieter Ruijten, (D) a Laura Trullemans, (D) a \\ Tom Renders, (D) a Peter Van Puyvelde, ${ }^{b}$ Hilda Witters ${ }^{c}$ and Bert F. Sels (D) *a
}

Bisguaiacol F (BGF), a potentially safer and renewable bisphenol A (BPA) replacement made from ligninderivable vanillyl alcohol ( $p-\mathrm{VA})$, is a promising building block for future aromatic biopolymers. Unfortunately, like BPA synthesis, this electrophilic condensation reaction is also prone to regioselectivity issues, giving rise to $m, p^{\prime}$ - and $O, p^{\prime}$-BGF byproducts. In this work, the hitherto unconsidered influence of $m, p^{\prime}$-BGF, viz. the main isomeric byproduct of $p, p^{\prime}$-BGF synthesis, on the physicochemical properties of poly(BGF carbonate) (BGF-PC) was systematically investigated by random copolymerisation with different fractions of pure $m, p^{\prime}-\operatorname{BGF}(25,50$ and $75 \mathrm{wt} \%)$. To do so, the elusive $m, p^{\prime}$-isomer was made in unparalleled regioselectivity $(72 \%)$ by alkylation condensation of isovanillyl alcohol ( $m$-VA) with guaiacol. Surprisingly, no isomeric scrambling due to acid-catalysed isomerisation was encountered for pure BGF isomers, which strongly facilitates their synthesis in contrast to petrochemical bisphenol $F$ (BPF). Furthermore, to ensure safer chemical design, an in vitro human oestrogen receptor $\alpha(\mathrm{hER} \alpha)$ transactivation assay was performed. Both pure $m, p^{\prime}-$ and $p, p^{\prime}$-BGF displayed a significantly reduced oestrogenic potency ( 426-457 times lower affinity than BPA) and oestrogenic efficacy ( 39-50\% of BPA's maximum induction). Interestingly, mutual comparison between $p, p^{\prime}$-BPF and $p, p^{\prime}$-BGF reveals and proves for the

Received 26th July 2019, Accepted 2nd October 2019 DOI: $10.1039 / c 9 g c 02619 c$ rsc.li/greenchem first time the direct link between ortho-methoxy substitution and reduced in vitro oestrogenic activity (for transactivation of $\mathrm{hER} \alpha$ ). In contrast to o, $p^{\prime}-\mathrm{BPA}$, viz. the main byproduct of $p, p^{\prime}$-BPA synthesis, $m, p^{\prime}-\mathrm{BGF}$ was proven suitable for utilization in thermoplastics, thereby avoiding time-consuming and labour-intensive (re)crystallizations to obtain regioisomerically pure $p, p^{\prime}$-BGF.

\section{Introduction}

The future of biomass as an alternative resource for the polymer industry depends strongly on incorporating renewable platform chemicals into existing petrochemical processes to obtain bio-based products. ${ }^{1,2}$ Studies have shown that bisguaiacol F (BGF), made from lignin-derivable vanillyl

\footnotetext{
${ }^{a}$ Dept. of Microbial and Molecular Systems $\left(M^{2} S\right)$, Centre for Sustainable Catalysis and Engineering (CSCE), KU Leuven, Celestijnenlaan 200F, 3001 Leuven, Belgium. E-mail: stef.koelewijn@kuleuven.be, bert.sels@kuleuven.be

${ }^{b}$ Dept. of Chemical Engineering, Soft Matter, Rheology and Technology (SMaRT), KU Leuven, Celestijnenlaan 200F, 3001 Leuven, Belgium

${ }^{c}$ Dept. of Health, Applied Bio \& molecular Systems (ABS), Flemish Institute for Technological Research (VITO), Boeretang 200, 2400 Mol, Belgium

$\dagger$ Electronic supplementary information (ESI) available: Full characterisations of BGF regioisomers $\left[1 \mathrm{D}{ }^{1} \mathrm{H}\right.$ and ${ }^{13} \mathrm{C}$ (DEPT) NMR, 2D ${ }^{1} \mathrm{H},{ }^{13} \mathrm{C}$ HMBC NMR, (GC-) MS, FT-IR, DSC and XRD analyses]. Chromatographic data for ACI of BPF in guaiacol. Additional experimental details of the in vitro transactivation assay. Additional polymer characterisations $\left({ }^{1} \mathrm{H}\right.$ and ${ }^{13} \mathrm{C}$ NMR and FT-IR). See DOI: $10.1039 / \mathrm{c} 9 \mathrm{gc} 02619 \mathrm{c}$
}

alcohol, ${ }^{3,4}$ could potentially replace bisphenol A (BPA) as a structural analogue in the preparation of aromatic epoxy resins, ${ }^{5,6}$ polycarbonates, ${ }^{7}$ and polyesters. ${ }^{8}$ Moreover, the safety-driven molecular design of BGF is expected to minimise adverse effects on human health and the environment related to oestrogenic endocrine disruption as present for BPA and its regrettably no less harmful substitutions, such as bisphenol $\mathrm{S}$ (BPS) and $\mathrm{F}(\mathrm{BPF}) .^{9-11}$

BPF, like BPA, is typically made by Brønsted acid-catalysed hydroxyalkylation/alkylation condensation between formaldehyde and a large excess of phenol under mild conditions (Fig. 1A). BPF is structurally the most simple albeit technically the most difficult bisphenol to make. Formaldehyde, in contrast to acetone, is more reactive, readily leading to unwanted phenolic oligomers, and it bears less steric hindrance to direct desirable $p, p^{\prime}$-coupling. ${ }^{12}$ For instance, whereas (un)promoted BPA synthesis predominately yields $p, p^{\prime}$-isomers ( $\sim 88-95 \%$ $p, p^{\prime}$-BPA, $\sim 5-13 \% \quad o, p^{\prime}$-BPA and negligible $\left.o, o^{\prime}-\mathrm{BPA}\right){ }^{13-15}$ similar BPF synthesis leads to a mixture of isomers, in which $o, p^{\prime}$-isomers are most prominent ( $\sim 30-38 \% p, p^{\prime}-\mathrm{BPF}, 47-49 \%$ 
Petro-based - formaldehyde and phenol to BPF

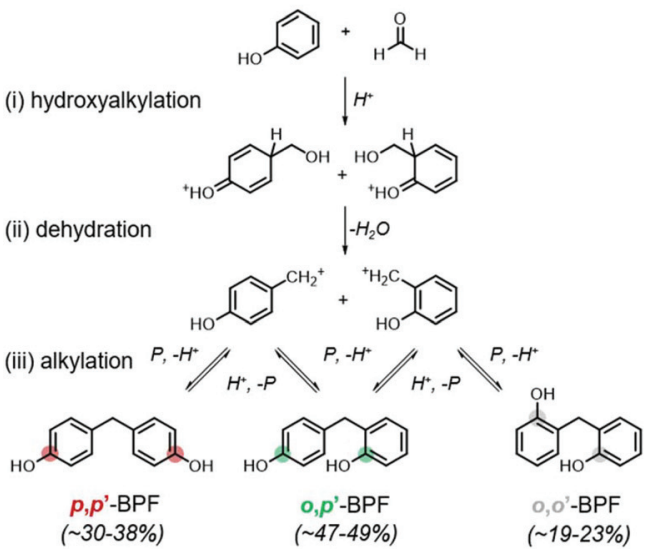

Bio-based - vanillyl alcohol and guaiacol to BGF

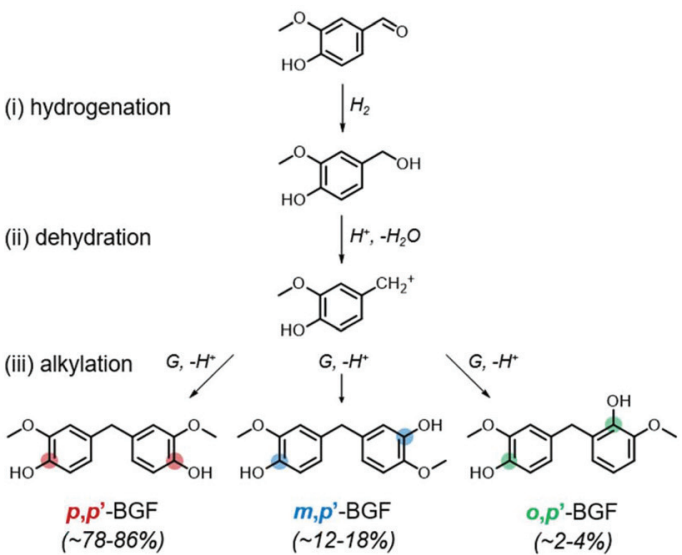

Fig. 1 Brønsted acid-catalysed (A) hydroxyalkylation/alkylation condensation between petro-based formaldehyde and phenol to bisphenol $\mathrm{F}$ (BPF) isomers, and (B) alkylation condensation between bio-based vanillyl alcohol - obtainable by hydrogenation of vanillin - and guaiacol to bisguaiacol $\mathrm{F}(\mathrm{BGF})$ isomers. Notice the differences in the types of isomers and their distribution. Abbreviations: $\mathrm{P}=\mathrm{phenol}, \mathrm{G}=\mathrm{guaiacol}$. $o, p^{\prime}-\mathrm{BPF}$ and $19-23 \% \quad o, o^{\prime}$-BPF). ${ }^{16,17}$ BPF's unfavourable thermodynamic equilibrium in concert with acid-catalysed isomerisation prevents (kinetically controlled) regioselective $p, p^{\prime}$ $\mathrm{BPF}$ formation, at the cost of (thermodynamically controlled) $o, p^{\prime}$ - and $o, o^{\prime}$-isomers. ${ }^{13,18}$ Although some methods have enabled higher $p, p^{\prime}$-BPF selectivity (up to $76 \%$ ), ${ }^{12,19-22}$ improved regio-selectivity towards $p, p^{\prime}$-BPF remains a scientific challenge of high industrial relevance. The molar isomeric ratio plays an importance role, for instance in synthesising polycarbonates (PCs) with improved physicochemical properties such as colour stability, crystallinity, and intermolecular attractive forces between polymer chains. ${ }^{15,23,24}$ Most commercial applications require isomeric separation by energy-intensive procedures involving fractional distillation coupled with crystallisation. In the case of BPA, the presence of up to $5 \%$ unusable $o, p^{\prime}$-BPA in the reaction product requires significant purification effort to achieve the $>99.5 \%$ BPA purity level required for PCs. ${ }^{15}$

BGF, the renewable BPF variant, is made by Brønsted acidcatalysed alkylation condensation between vanillyl alcohol ( $p$-VA) and guaiacol (i.e. 2-methoxyphenol) - without hydroxyalkylation - under mild conditions (Fig. 1B).,25,26 Both reagents exert a profound impact on regioselectivity. The reactivity and (para-)orientation of the hydroxymethyl moiety of $p$-VA, made by selective hydrogenation of lignin-derivable vanillin, ${ }^{3,4}$ omit the use of harmful carcinogenic formaldehyde and (undesirable ortho-)hydroxymethylation. Strikingly, Hernandez et al. (2016) reported that bio-based BGF synthesis - in contrast to petro-based BPF - delivers (i) mainly desirable $p, p^{\prime}$-isomers ( 78-86\%), (ii) low amounts of undesirable $o, p^{\prime}$ BGF $(\sim 2-4 \%)$, but (iii) a significant share of unconventional $m, p^{\prime}$-BGF isomers $(\sim 12-18 \%) .{ }^{5}$ Moreover, upon reacting $p$-VA with syringol (i.e. 2,6-dimethoxyphenol) instead of guaiacol, $m, p^{\prime}$-linkages become dominant. ${ }^{27}$ The high tendency for $m, p^{\prime}$ coupling (relative to phenolic $\mathrm{OH}$ ) arises from the combined effect of ortho position unavailability, and electron donation from the $o$-methoxyl(s).

In the present work, we investigated this atypical $m, p^{\prime}$-BGF isomer according to the principle of safety-driven molecular design, asking ourselves if pure $m, p^{\prime}$-BGF (combined with $p, p^{\prime}$ BGF) is not only functional for utilization but, above all, safe. More specifically, the present work systematically studied the effect of $m, p^{\prime}$-BGF on (i) the in vitro transactivation of human oestrogen receptor $\alpha(\mathrm{hER} \alpha)$ in a luciferase reporter gene assay, and (ii) the physicochemical properties of (co)poly(BGF carbonate) made by random copolymerisation. To do so, $m, p^{\prime}-$ BGF is obtained selectively through modified acid-catalysed BGF synthesis from isovanillyl alcohol ( $m$-VA), i.e. a commercially available isomer of $p$-VA. This latter finding prompted us to probe into the hitherto unstudied acid-catalysed isomerisation of BGF isomers as well.

If the above questions are answered positively, valorisation of a significant byproduct will be possible, which is beneficial for carbon efficiency. Moreover, it could strongly reduce the number of purification steps needed to obtain useful BGF since the sum of $p, p^{\prime}$ - and $m, p^{\prime}$-isomers amounts to $96-98 \%$, leaving only $2-4 \%$ undesirable $o, p^{\prime}$-BGF.

\section{Results and discussion}

\section{Regioselective acid-catalysed synthesis (ACS)}

Although previously reported yields of total BGF were fairly high ( $\sim 70 \mathrm{wt} \%$, next to higher $M_{\mathrm{w}}$ oligomers), ${ }^{5}$ isolation of $m, p^{\prime}$-BGF ( $\sim 8-13 \mathrm{wt} \%$ of the crude reaction mixture) would be an arduous purification process. Consequently, selective synthesis of $m, p^{\prime}$-BGF was attempted through modified acid-catalysed BGF synthesis from isovanillyl alcohol ( $m$-VA), which is a $p$-VA isomer with the hydroxymethyl moiety at the meta position to the phenolic $\mathrm{OH}$. A general scheme of this regioisomer 
General strategy - use of VA isomers

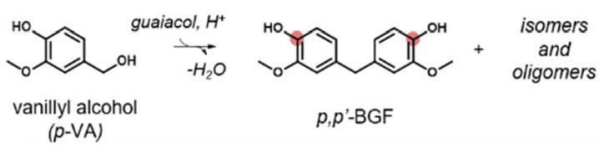

strategy is presented in Fig. 2A. Since the isomeric equilibrium at a given temperature is dictated by thermodynamics, temperature was set as low as possible to anticipate kinetically controlled products, but high enough to retain conversion and reaction mixture homogeneity $\left(T_{\mathrm{m}}\right.$, guaiacol $\left.=28{ }^{\circ} \mathrm{C}\right)$.

As an initial entry, $m$-VA as well as $p$-VA (control) was reacted with guaiacol at $40{ }^{\circ} \mathrm{C}$ for $8 \mathrm{~h}$, using the strongly acidic sulfonated ion-exchange resin Amberlyst $₫$-15. For $p$-VA, GC-FID analysis after trimethylsilylation of the crude reaction mixture discriminated three clear signals, indicative of $o, p^{\prime}$-, $m, p^{\prime}$ - and $p, p^{\prime}$-BGF isomers (Fig. 2B). The second largest $m, p^{\prime}$ signal coincided with the main signal obtained starting from $m$-VA (Fig. 2B, blue). Based on both this retention overlap and its fragmentation pattern (Fig. S3E $\dagger$ ), the overlapping signal was tentatively assigned to $m, p^{\prime}$-BGF. Indeed, MS analysis gave indistinguishable fragmentation patterns for $p, p^{\prime}$-BGF (Fig. S2E $\dagger$ ) and $m, p^{\prime}$-BGF (Fig. S3E $\dagger$ ) and is as such inconclusive. After purification of the crude product mixture, the main molecular identity was verified by multiple techniques (Fig. $\mathrm{S} 2 \uparrow$ for $p, p^{\prime}$-BGF and Fig. $\mathrm{S} 3 \uparrow$ for $m, p^{\prime}$-BGF). In general, ${ }^{1} \mathrm{H}$ and ${ }^{13} \mathrm{C}$ NMR analyses showed a near doubling in the amount of resonances (relative to $p, p^{\prime}-\mathrm{BGF}$ ), indicating structural symmetry loss (Fig. S3B and $\mathrm{C} \dagger$ ). Noteworthy ${ }^{1} \mathrm{H}$-indicators were (i) the upfield shift of the $-\mathrm{CH}_{2}-$ singlet (3.85 to $3.81 \mathrm{ppm}$ ), and (ii) the coupling pattern analysis of the aromatic protons. According to the asymmetry and the proposed ring substitution, coupling patterns indeed allowed for identifying four doublets and two doublets of doublets (see details in Fig. S5†). Full structure assignment was done with the help of $2 \mathrm{D}{ }^{1} \mathrm{H},{ }^{13} \mathrm{C}$ HMBC spectra of the aliphatic-aromatic and hydroxylic-aromatic domains (Fig. S3D †). Finally, FT-IR indicated the presence of aromatic hydroxyls, showing a broad $\mathrm{O}-\mathrm{H}$ stretch at $3433 \mathrm{~cm}^{-1}$ (Fig. S3F $\dagger$ ). Altogether, this set of characterisation
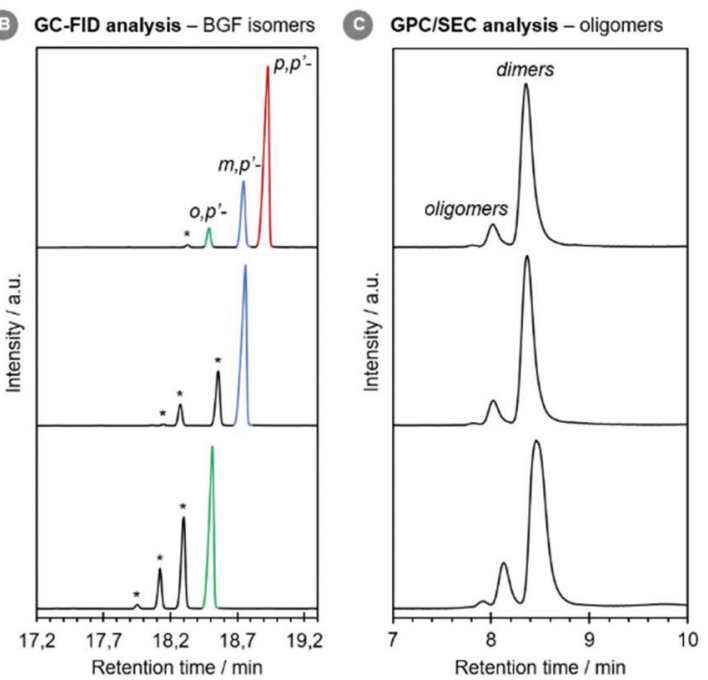

studies unambiguously proves the successful regio-selective synthesis and isolation of $m, p^{\prime}$-BGF from $m$-VA and guaiacol.

To further confirm the validity of the methodology, orthovanillyl alcohol $(o-\mathrm{VA})$ was reacted with guaiacol as well. Since in $o$-VA the hydroxylmethyl moiety is positioned ortho to the phenolic $\mathrm{OH}, o, p^{\prime}$-BGF is expected as the main product. Conforming to our hypothesis, the major product signal perfectly coincided with the third largest control signal (Fig. 2B, green). Unlike for $p, p^{\prime}$ - and $m, p^{\prime}$-BGF, MS data for this signal contained main mass spectral signals at $\mathrm{m} / \mathrm{z} 124$ and 137 (Fig. S4E†), likely caused by the ortho-hydroxy hydrogen interacting with the neighbouring aromatic ring, as also found for $o, p^{\prime}$-BPA. ${ }^{28}$ Pure $o, p^{\prime}$-BGF was also fully identified by $1 \mathrm{D}^{1} \mathrm{H}$ and ${ }^{13} \mathrm{C}$ NMR, and $2 \mathrm{D}{ }^{1} \mathrm{H},{ }^{13} \mathrm{C}$ NMR (Fig. S4B-D $\dagger$ ). Definite proof for $o, p^{\prime}$-coupling was found in the aliphatic-aromatic HMBC spectral region showing a unique three-bond ${ }^{1} \mathrm{H},{ }^{13} \mathrm{C}$ correlation between the bridging methylene protons and the phenolic carbon $\left(\mathrm{H}_{\mathrm{a}}: 3.92 ; \mathrm{C}_{1 *}: 143.9 \mathrm{ppm}\right)$. Further support came from the FT-IR spectral fingerprint region, showing a distinct absorption band at $746 \mathrm{~cm}^{-1}$, indicating out-of-plane $\mathrm{C}-\mathrm{H}$ bending motions of the three neighbouring ring protons, a unique feature of the ortho-coupled ring (Fig. $\mathrm{S} 4 \mathrm{~F} \dagger$ ).

Crude product mixtures were retroactively quantified by GC-FID analyses calibrated against the pure BGF isomers to study reaction chemo- and regioselectivity. In all three cases, chemoselectivity (i.e. total BGF) was constant at about $55-58 \mathrm{wt} \%$, indicating significant formation of higher $M_{\mathrm{w}}$ oligomers as confirmed by GPC/SEC-UV analysis in THF (Fig. 2C). Regarding regio-selectivity, $m, p^{\prime}$-BGF synthesis from $m$-VA and guaiacol yielded $72 \% m, p^{\prime}-, 21 \% m, m^{\prime}-, 7 \% o, m^{\prime}$-BGF, and $<1 \%$ others, compared to $73 \% p, p^{\prime}$-, $21 \% m, p^{\prime}$-, $6 \% o, p^{\prime}$ $\mathrm{BGF}$, and $<1 \%$ others for the control $p, p^{\prime}$-BGF reaction. Regioselectivity towards $o, p^{\prime}$-BGF was lower $\left(57 \% o, p^{\prime}\right.$-, $29 \%$ 
$o, m^{\prime}$-, $13 \% o, o^{\prime}$-BGF, $<1 \%$ others). The molecular identities of foregoing unreported $m, m^{\prime}-, o, m^{\prime}$ - and $o, o^{\prime}$-isomers (Fig. S1†) are provisional albeit plausible based on (i) steric and electronic effects of guaiacol, and (ii) the coincidence of $o, m^{\prime}$-retention times (Fig. 2B).

Laboratory quantities of high purity bisguaiacols (>99.5\%) were made via successive (re)crystallisation, which hereafter warrants and enables clear interpretation of structure-activity and structure-property relationships with regard to safety and functionality testing, respectively. Each isomer was obtained in a solid crystalline form (Fig. S6 $\dagger$ ) as confirmed by (i) sharp melting endotherms (99-100 ${ }^{\circ} \mathrm{C}$ for $p, p^{\prime}$-BGF, $119-120{ }^{\circ} \mathrm{C}$ for $m, p^{\prime}$-BGF, and $103-105{ }^{\circ} \mathrm{C}$ for $o, p^{\prime}$-BGF) as seen in DSC (Fig. S7A $\dagger$ ) and (ii) clear X-ray diffraction (XRD) peaks as seen in XRD analyses (Fig. S7B $\dagger$ ). Interestingly, also another polymorph was detected for $p, p^{\prime}$-BGF by DSC $\left(T_{\mathrm{m}}=105-106{ }^{\circ} \mathrm{C}\right)$ and confirmed by XRD (Fig. S7 $\dagger$ ). This resolves the prior melting point discrepancy found in the literature. ${ }^{5,29}$

\section{Acid-catalysed isomerisation (ACI)}

Instigated by the remarkable finding that BGF regio-selectivity can be tuned via proper VA isomer selection, we hypothesised that BGF isomers are unable to interconvert by acid-catalysed isomerisation (ACI), unlike previously observed for bisphenols such as $\mathrm{BPA},{ }^{23,30} \mathrm{BPF},{ }^{18} \mathrm{BPS},{ }^{31}$ bisphenol C (BPC), ${ }^{32}$ and diphenolic acid (DPA). ${ }^{33}$ For bisphenols, isomerisation typically acts in concert with synthesis since both are acid-catalysed. To allow clear interpretation, the following reactions were preferably performed with $p, p^{\prime}$-BGF due to its structural resemblance to petro-based $p, p^{\prime}$-BPF.

To test the proposed theory, in a first set-up, $p, p^{\prime}$-BGF synthesis was conducted at prolonged reaction time to monitor possible changes in isomeric distribution due to ACI. Even after $144 \mathrm{~h}$ at $80{ }^{\circ} \mathrm{C}-$ not $40{ }^{\circ} \mathrm{C}$ as during the ACS - with Amberlyst-15®, no significant change in isomer distribution was observed (69\% $p, p^{\prime}-, 24 \% m, p^{\prime}, 7 \% o, p^{\prime}$-BGF, <1\% others).

To further corroborate our hypothesis, ACI of isomerically pure BGF samples was attempted. Possible confinement effects were excluded by substituting porous macroreticular Amberlyst ${ }^{\circledR}-15$ by para-toluene sulfonic acid ( $p$-TSA), a related homogeneous sulfonic acid. Indeed, upon reacting $p, p^{\prime}$-BGF and guaiacol at $80{ }^{\circ} \mathrm{C}$ in the presence of $p$-TSA, $o, p^{\prime}$-BGF was obtained in only $1 \%$ yield after $144 \mathrm{~h}$, and almost no $m, p^{\prime}$ isomer was observed (Fig. 3A). In contrast, for an isomerically pure sample of petrochemical $p, p^{\prime}$-BPF (control), identical conditions led to significant isomeric scrambling in only a few hours, yielding 54.3\% o, $p^{\prime}$ - and $8.7 \% \quad o, o^{\prime}$-BPF after $144 \mathrm{~h}$ (Fig. 3B). To rule out the possibility of working at the thermodynamically controlled isomeric equilibrium, both pure $m, p^{\prime}$ BGF and $o, p^{\prime}$-BGF were reacted under similar conditions as well, but again no isomeric scrambling was detected (data not shown). For the applied conditions, it was therefore concluded that ACI of BGF isomers in guaiacol is either extremely slow, or even non-existing.

Finally, after demonstrating the absence of isomer interconversion, we assessed whether acid-catalysed cleavage (ACC) would be impossible. Namely, for petro-based BPF, ACI occurs through aromatic ring protonation, enabling $\mathrm{C}-\mathrm{C}$ bond cleavage at the methylene bridge in the reverse direction of the electrophilic aromatic substitution (Fig. 1A, bottom part). To test this, we reacted $p, p^{\prime}$-BGF with phenol instead of guaiacol as the solvent/reactant and investigated the resulting product distribution after $48 \mathrm{~h}$. While the transient carbocation intermediate was undetectable by GC-FID analysis, the presence of guaiacol in the reaction medium confirms the possibility for ACC of $p, p^{\prime}$-BGF in phenol. Furthermore, qualitative GC/MS analysis after trimethylsilylation of the product mixture revealed several smaller peaks with parent mass spectral signals at 374 and $344 \mathrm{~m} / \mathrm{z}$. These signals are consistent with the molecular weights of trimethylsilylated species of BGF in which either one or two guaiacol rings are displaced by phenol, respectively.

Overall, these preliminary findings confirm that regioselective ACS of BGF isomers is possible because ACI of BGF isomers is practically absent under the applied reaction conditions. The aromatic solvent (guaiacol) seems to play a decisive role by hindering ACC, as ACC of $p, p^{\prime}$-BGF isomers in phenol was proven. Indeed, ACC of petro-based $p, p^{\prime}$-BPF in guaiacol - compared to ACI of $p, p^{\prime}$-BPF in phenol (Fig. 3B) resulted in only limited conversion of $p, p^{\prime}$-BPF $(20 \%$ after

\section{GC-FID analysis - pure petro-based $p, p^{\prime}-$ BPF in phenol}

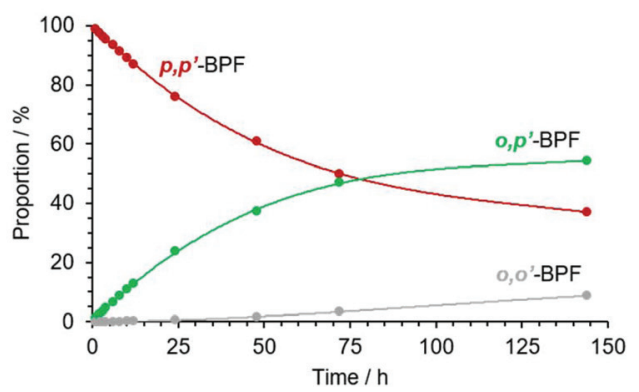

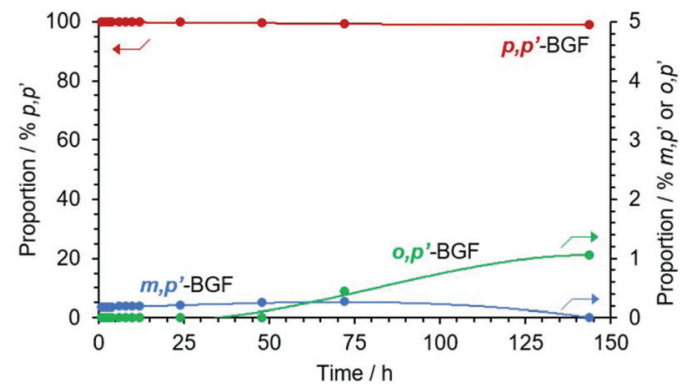

Fig. 3 Isomeric distribution against time $(0-144 \mathrm{~h})$ upon reacting isomerically pure (A) $p, p^{\prime}$-BGF with guaiacol, or (B) $p, p^{\prime}-\mathrm{BPF}$ with phenol in the presence of a homogeneous sulfonic acid (i.e. $p$-TSA). Conditions: $14 \mathrm{mmol}\left(o\right.$-methoxy)phenol, $2 \mathrm{mmol} p, p^{\prime}$-isomer, $0.12 \mathrm{mmol} \mathrm{H}^{+}, 80^{\circ} \mathrm{C}$. 
$144 \mathrm{~h}$ ) into mono-methoxylated BPF species through exchange of one of the phenol rings with guaiacol (Fig. S8†). Di-methoxylated BPF species were not detected. Follow-up research is currently ongoing to deepen the mechanistic insight.

\section{In vitro human oestrogen receptor $\alpha(\mathrm{hER} \alpha)$ activity}

To corroborate the - in theory - safe(r) chemical design of bisguaiacol scaffolds, and to avoid future regrettable BPA substitutions, the endocrine-disrupting potential of $m, p^{\prime}$-BGF as well as $p, p^{\prime}$-BGF was evaluated prior to polymerisation. Thereto, their interference with hER $\alpha$ was studied, and benchmarked against the natural hormone oestradiol (17 $\beta$-E2), and synthetic xeno-oestrogens BPA and BPF. Fig. 4 displays the in vitro hER $\alpha$ transactivation by the luciferase reporter gene assay using transgenic human MELN cells (details in the ESI $\dagger$ ). The results were evaluated in terms of potency (i.e. concentration needed for a given effect, expressed as $\mathrm{EC}_{50}$ ) and efficacy (i.e. maximum effect induced for a given compound, expressed as $\left.E_{\text {max }}\right)$. Efficacy is an essential supplement to potency as a reduced effect caused by partial agonists is not taken into account by the $\mathrm{EC}_{50}$, irrespective of whether a partial response was obtained. Table 1 summarizes $\mathrm{EC}_{50}$ and $E_{\max }$ values, and also lists the (log-transformed) relative estrogenic potency (REP) and estrogenic efficacy (REE) to $17 \beta-\mathrm{E} 2$, commonly used to compare oestrogenic endpoints in the literature.

Based on the luciferase reporter gene assay, 17 $\beta$-E2, BPA and BPF fully activated hER $\alpha$ ( $\sim$ six-to-eight fold induction; $577-760 \%)$ in a dose-dependent manner at concentrations of $10^{-12}-10^{-9}, 10^{-8}-10^{-5}$, and $10^{-8}-10^{-4} \mathrm{M}$, respectively. $\mathrm{EC}_{50}$ values of $17 \beta$-E2, BPA and BPF were $1.3 \times 10^{-11}, 6.6 \times 10^{-7}$ and $1.4 \times 10^{-6} \mathrm{M}$, accordingly. Only partial dose-response curves (up to two-to-three fold induction; 225-289\%) were obtained for $m, p^{\prime}$ - and $p, p^{\prime}$-BGF, starting at concentrations higher than $10^{-5} \mathrm{M}$, with respective $\mathrm{EC}_{50}$ values of $8.7 \times 10^{-5}$ and

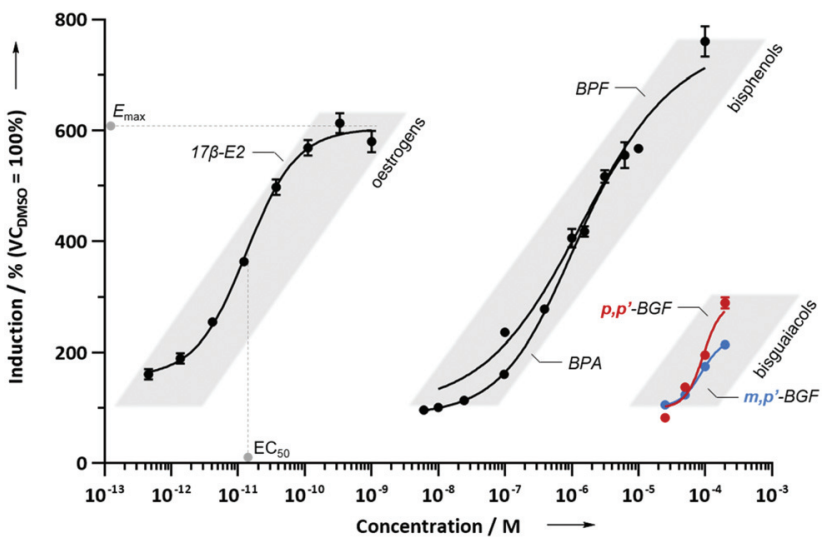

Fig. 4 Concentration-dependent in vitro transcriptional induction of luciferase by $17 \beta-E 2, B P A, B P F$, and $p, p^{\prime}-B G F$ and $m, p^{\prime}-B G F$ in MELN$h E R \alpha$ cells. Values (mean $\pm S D$, tested in triplicate) are expressed as the percentage of luciferase induction by the solvent control (set as $100 \%$ ). Three distinct induction regions for oestrogens, bisphenols and bisguaiacols were indicated in grey. $\mathrm{EC}_{50}$ and $E_{\max }$ value determination is exemplified for $17 \beta$-E2.
Table 1 Half-maximal effective concentration $\left(E C_{50}\right)$, relative oestrogenic potency (REP), maximal luciferase induction $\left(E_{\text {max }}\right)$, and relative oestrogenic efficacy (REE) in MELN-hER $\alpha$ cells $^{a}$

\begin{tabular}{llllll}
\hline Compound & $\mathrm{EC}_{50} / \mathrm{M}$ & $\mathrm{REP}^{b} / \%$ & $\log _{10} \mathrm{REP} /-$ & $E_{\max } / \%$ & $\mathrm{REE}^{c} \%$ \\
\hline $17 \beta-\mathrm{E} 2$ & $1.3 \times 10^{-11}$ & $1.0 \times 10^{2}$ & +2.00 & 603 & 100 \\
$p, p^{\prime}-\mathrm{BPA}^{d}$ & $6.6 \times 10^{-7}$ & $6.5 \times 10^{-3}$ & -2.19 & $577^{e}$ & $96^{e}$ \\
$p, p^{\prime}-\mathrm{BPF}$ & $1.4 \times 10^{-6}$ & $1.0 \times 10^{-3}$ & -3.02 & $760^{f}$ & 126 \\
$p, p^{\prime}-\mathrm{BGF}$ & $9.4 \times 10^{-5}$ & $1.4 \times 10^{-5}$ & -4.85 & $289^{f}$ & 48 \\
$m, p^{\prime}-\mathrm{BGF}$ & $8.7 \times 10^{-5}$ & $1.5 \times 10^{-5}$ & -4.82 & 225 & 37
\end{tabular}

${ }^{a}$ Each compound was tested in triplicate and reported data are mean $\mathrm{EC}_{50}$ and $E_{\max }$ values. ${ }^{b}$ Calculated as the ratio of $\mathrm{EC}_{50}\left(17 \beta\right.$-E2) to $\mathrm{EC}_{50}$ (compound) $\times 100 .{ }^{c}$ Calculated as the ratio of $E_{\max }$ (compound) to $E_{\max }(17 \beta$-E2 $) \times 100 .{ }^{d}$ Data from the previous unpaired experiment with $\mathrm{EC}_{50}(17 \beta-\mathrm{E} 2)=4.3 \times 10^{-11} \mathrm{M}^{34}{ }^{e}$ Induction values rescaled based on the ratio of $E_{\max }(17 \beta-\mathrm{E} 2)$ values. ${ }^{f}$ Top and bottom value constrained during non-linear regression.

$9.4 \times 10^{-5} \mathrm{M}$. In other words, compared to BPA and BPF, both BGF isomers displayed a significantly reduced potency ( 426-457 times lower affinity than BPA) and efficacy ( $\sim 39-50 \%$ of BPA's maximum induction).

Careful generalisation of the results allowed identifying two distinct regions that concentrate the dose-response curves of either bisphenols ( $\sim \mathrm{EC}_{50}$ in the $1 \mu \mathrm{M}$ range) or bisguaiacols ( $\sim \mathrm{EC}_{50}$ in the $100 \mu \mathrm{M}$ range) (Fig. 4). Inter- and intra-regional comparison delivers valuable insight. Firstly, as bio-based $p, p^{\prime}-$ BGF does only differ from petro-based $p, p^{\prime}$-BPF in terms of its $o$-methoxy groups, these groups can be unambiguously identified as the root cause for the significant drop in in vitro oestrogenic activity, reducing both potency (by about two orders) and efficacy (by $>50 \%$ ). Noticeably, lower in vitro oestrogenic activities were already reported for 4-alkylated $m, m^{\prime}$-BGFs and $m, m^{\prime}$ bissyringol Fs (BSFs), ${ }^{34,35}$ although the hypothesised link with the methoxy groups could then not be unambiguously established due to the inaccessibility of non-methoxylated analogues. Taken together, these results clearly illustrate the positive effect of incorporating $o$-methoxy moieties into bisphenol scaffolds on lowering in vitro oestrogenic transactivation, both in terms of potency and efficacy. Secondly, the absence (or presence) of methyl groups on the methylene bridge seems to be less decisive. Namely, the in vitro oestrogenic activities expressed in terms of (relative) potency - for the bisphenols $\mathrm{BPF}$ (no methyl, $\mathrm{EC}_{50}=1.4 \mu \mathrm{M}, \mathrm{REP}=1.0 \times 10^{-3} \%$ ), BPE (one methyl, $\left.\mathrm{EC}_{50}=1.4 \mu \mathrm{M}, \mathrm{REP}=3.1 \times 10^{-3} \%\right)^{34}$ and BPA (two methyl, $\mathrm{EC}_{50}=0.7 \mu \mathrm{M}, \mathrm{REP}=6.5 \times 10^{-3} \%$ ) were comparable. The same seems to be valid for $p, p^{\prime}$-BGF (no methyl, REP = $1.4 \times 10^{-5} \%$ ) and $p, p^{\prime}$-bisguaiacol A (BGA, two methyl), as the latter was unable to displace (50\% of radio-labeled) oestradiol in a competitive binding assay for hER $\alpha$ and hER $\beta 1$ at concentrations up to $250 \mu \mathrm{M}\left(\mathrm{REP}=<0.4-3.3 \times 10^{-5} \%\right.$, calculated from $\mathrm{IC}_{50}$ values). ${ }^{36}$ Finally, by comparing $m, p^{\prime}$-BGF and $p, p^{\prime}-$ $\mathrm{BGF}$, regioisomerism seems to only affect in vitro oestrogenic activity in terms of efficacy ( $E_{\max }$ and REE). As the aromatic hydroxyl group of $17 \beta$-E2 is ideally para-oriented for optimal activity, ${ }^{37}$ the reduced induction for $m, p^{\prime}$-BGF most likely 
1 results from the halved contribution of such para-oriented hydroxyl groups.

As such, this is the first study reporting in vitro oestrogenic $\mathrm{hER} \alpha$ transactivation data for isomerically pure $m, p^{\prime}$-BGF. ${ }^{38}$ Notably, our control $p, p^{\prime}$-BGF findings were consistent with recent findings of Szafran et al. (2017), who tested $p, p^{\prime}$-BGF using a related MCF-7 cell model. ${ }^{11}$ At a concentration of $5 \times$ $10^{-6} \mathrm{M}, p, p^{\prime}$-BGF demonstrated no oestrogenic activity, while BPA treatment gave a significant oestrogenic response $(57 \%$ of the $17 \beta$-E2 response at $10^{-9} \mathrm{M}$ ). Also the closely related $p, p^{\prime}$ oriented 4,4'-ethylenebis(2-methoxyphenol) (Fig. 5A), made by self-metathesis of isoeugenol followed by double bond hydrogenation, ${ }^{39,40}$ displayed no in vitro oestrogenic activity in a yeast (o)estrogen screen (YES) assay at concentrations up to $3 \times 10^{-6} \mathrm{M}^{40}$ At similar concentrations, BPA-induced hER $\alpha$ activation equals that of $17 \beta$-E2 at $2 \times 10^{-10} \mathrm{M}$. Concentrations above $3-5 \times 10^{-6} \mathrm{M}$ were unfortunately not reported for both studies. However, for instance, our previous findings for 5-methylated $p, p^{\prime}$-BGF ( $p, p^{\prime}$-BGF-5 M; Fig. 5B), ${ }^{34}$ viz. 4,4'methylenebis(2-methoxy-5-methylphenol), showed that the dose-response curve only began at $5 \times 10^{-6} \mathrm{M}$ (or even $2 \times 10^{-5}$ $\mathrm{M}$ in this study). Future in vitro studies concerning $o$-methoxysubstituted bisphenols should hence preferably also test the highest possible concentrations, up to the solubility limit, allowing a fair comparison that supports and enables molecular design of safer chemicals.

Though very promising, these results should be considered with care. Namely, in vitro assays do not fully represent the circumstances present in living organisms, for instance, not covering metabolic effects. Additional in vivo screening is thus tors, such as the androgen and thyroid hormone receptor, should also be evaluated. This is work in progress.

\section{Random copolymerisation into aromatic polycarbonate (PC)}

Encouraged by the significantly lower in vitro oestrogen activity, these renewable and safer bisphenols were assessed for their functionality in polymer synthesis. Previously, biobased epoxy thermosetting resins were successfully made by BGF (DGEBG) - a methoxylated equivalent of the diglycidyl ether of $p, p^{\prime}$-BPF (DGEBF) - with a cycloaliphatic diamine (Amicure ${ }^{\circledR}$ PACM). Here, we aimed to synthesise thermoplastic (co-)PCs - the main end-use of BPA ( 64\% in 2018) ${ }^{41}$ - by
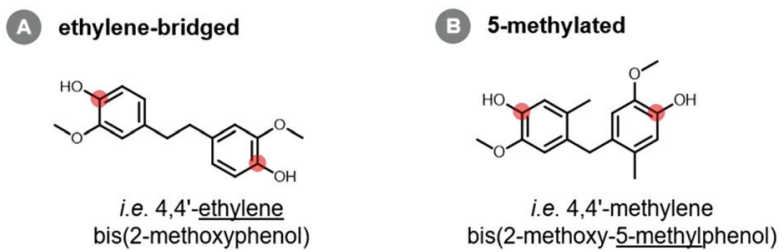

Fig. 5 Molecular structures of two closely related $p, p^{\prime}$-oriented bisguaiacol variants with similarly low in vitro oestrogenic activity reported in the literature. ${ }^{32,38}$ interfacial polycondensation with in situ-generated phosgene from triphosgene (i.e. a crystalline phosgene substitute). Although we are certainly aware of greener industrial nonphosgene $\mathrm{PC}$ production processes from $\mathrm{CO}_{2}$ ( $c f$. Asahi Kasei Process) still the vast majority of current PC production is phosgene-based ( 83\% in 2016). ${ }^{42,43}$ Moreover, SchottenBaumann conditions in concert with highly reactive (tri)phosgene facilitate to study possible differences in monomer reactivity, without resorting to high temperature and deep vacuum to favour the reversible transesterification equilibrium ( $c f$. melt polymerisation with diphenyl carbonate).

Polymerisation conditions were initially tuned to the synthesis of high $M_{\mathrm{w}}$ poly(BPA carbonate) (BPA-PC). Assuming that these optimal conditions also apply to $o$-methoxy bisphenols, identical conditions were thereafter used to polymerise pure $m, p^{\prime}$ - and $p, p^{\prime}$-BGF monomers, and 25/75, 50/50 and 75/ 25 mixtures thereof, to obtain the corresponding homo(BGF-PC) and copolymers (BGF-co-PC). Doing so, this copolymerisation study will not only give insight into $m, p^{\prime}$-BGF's influence on final polymer properties, but also on important process parameters such as monomer reactivity and solubility. Moreover, to establish valuable structure-property relationships, also poly(BPF carbonate) (BPF-PC) was made as a structurally identical albeit 'methoxy-free' reference to $p, p^{\prime}$-BGF-PC. Table 2 summarises the key characteristics, i.e., yield, $M_{\mathrm{w}}$ distribution and thermal properties. The results are discussed below.

All (co)polymerisations were successful and the PCs were formed in $>80 \%$ yield, except for BPF-PC (74\%). BPF-PC proved to be practically insoluble in DCM and thus precipitated during reaction, thereby limiting its yield. ${ }^{44}$ Interestingly, unlike BPF-PCs, BGF-based PCs were moderately soluble in DCM, which is undeniably linked to the additional methoxy groups. While BPA-PC was colourless (white), a pale tint of

Table 2 Key characteristics of BGF-(co-)PC benchmarked against BPA-PC, BPF-PC and BGA-PC ${ }^{a}$

\begin{tabular}{|c|c|c|c|c|c|c|}
\hline Type of (co)polymer & $\begin{array}{l}Y^{b} \\
{[\%]}\end{array}$ & $\begin{array}{l}\bar{M}_{\mathrm{W}}{ }^{c} \\
{[\mathrm{kDa}]}\end{array}$ & $\begin{array}{l}\bar{M}_{\mathrm{n}}{ }^{c} \\
{[\mathrm{kDa}]}\end{array}$ & $\begin{array}{l}Ð \\
{[-]}\end{array}$ & $\begin{array}{l}T_{\mathrm{g}}{ }^{d} \\
{\left[{ }^{\circ} \mathrm{C}\right]}\end{array}$ & $\begin{array}{l}T_{\mathrm{d}, \max }{ }^{e} \\
{\left[{ }^{\circ} \mathrm{C}\right]}\end{array}$ \\
\hline$p, p^{\prime}$-BPA-PC & 96 & 126 & 41 & 3.1 & 147 & 498 \\
\hline$p, p^{\prime}-\mathrm{BPA}-\mathrm{PC}^{f}$ & 81 & 16 & 4.5 & 3.6 & 134 & 474 \\
\hline$p, p^{\prime}-\mathrm{BPF}-\mathrm{PC}$ & 74 & - $g$ & — & $g^{g}$ & 114 & 447 \\
\hline$p, p^{\prime}-\mathrm{BGF}-\mathrm{PC}$ & 89 & 23 & 6.1 & 3.8 & 106 & 418 \\
\hline BGF-co-PC $(25 \%)^{h}$ & 92 & 21 & 5.7 & 3.7 & 106 & 417 \\
\hline BGF-co-PC $(50 \%)^{h}$ & 82 & 21 & 5.5 & 3.9 & 99 & 417 \\
\hline BGF-co-PC $(75 \%)^{h}$ & 85 & 26 & 6.2 & 4.2 & 109 & 419 \\
\hline$m, p^{\prime}-\mathrm{BGF}-\mathrm{PC}$ & 88 & 20 & 5.7 & 3.5 & 108 & 417 \\
\hline$p, p^{\prime}$-BGA-PC ${ }^{i}$ & n.r..$^{j}$ & 23 & 6.6 & 3.5 & 126 & 436 \\
\hline
\end{tabular}

${ }^{a}$ Reaction conditions and analytical procedures: see Experimental. ${ }^{b}$ Conditions were optimized for BPA-PC synthesis. ${ }^{c}$ Estimated by GPC/ SEC analyses in DCM against PS equivalents, except for BGA-PC (PCequivalents). ${ }^{d}$ Measured by DSC from $2^{\text {nd }}$ cooling at $10{ }^{\circ} \mathrm{C} \mathrm{min}^{-1}$ under $\mathrm{N}_{2}$. ${ }^{e}$ Calculated by TGA upon heating at $10{ }^{\circ} \mathrm{C} \min ^{-1}$ under $\mathrm{N}_{2}$, see also Table $\mathrm{S} 2 . \dagger{ }^{f}$ Reaction stopped after $1 \mathrm{~h} .{ }^{g}$ Not soluble in THF and DCM. ${ }^{h}$ Percent of $m, p^{\prime}$-BGF. ${ }^{i}$ Literature values. ${ }^{36}{ }^{j}$ n.r.: not reported. 
yellow was observed in both petro-based BPF- and bio-based BGF-PCs. The physical product appearance is shown in Fig. S9. $\dagger$

After (co)polymer recovery by precipitation, the molecular structures were verified by ${ }^{1} \mathrm{H}$ and ${ }^{13} \mathrm{C}$ NMR (Fig. S10 and $\mathrm{S} 11 \mathrm{~A} \dagger$ ), as well as by FT-IR spectroscopy (Fig. S13†). As concentrated BGF-( $\left.\mathrm{CO}^{-}\right) \mathrm{PCs}$ and BPF-PC were insoluble in common NMR solvents, spectra were recorded in a $10 \%(\mathrm{w} / \mathrm{w})$ mixture of TFA- $d$ in $\mathrm{CDCl}_{3}$, as they were insoluble in either pure TFA- $d$ or pure $\mathrm{CDCl}_{3}$. Previous research also resorted to this solvent mixture to dissolve high $M_{\mathrm{w}}$ polyesters like poly(glycolic acid) and poly(ethylene terephthalate). ${ }^{45}$ In contrast, PC samples with an isopropylidene instead of a methylene bridge, such as BPA-PC and literature-reported BGA-PC (i.e. o-methoxy-substituted BPA-PC), ${ }^{36}$ dissolved in pure $\mathrm{CDCl}_{3}$. Interestingly, as previously shown by our group, the $n$-propyl chains in $m, m^{\prime}$ BGF-4Ps made from 4-n-propylguaiacol improved PC's solubility. ${ }^{34}$

As illustrated in Fig. $6,{ }^{13} \mathrm{C}$ NMR analyses of the novel BGF(co-)PCs revealed (an) extra resonance(s) around $154 \mathrm{ppm}$ indicating carbonate ester moieties (Fig. 6A). The absence of phenolic ${ }^{1} \mathrm{H}$ resonances confirmed these findings (Fig. S11†). NMR data were further supported by FT-IR spectra, showing the introduction of characteristic carbonyl $(\mathrm{C}=\mathrm{O})$ stretches around $1781 \mathrm{~cm}^{-1}$ at the expense of phenolic $\mathrm{O}-\mathrm{H}$ stretches between 3600 and $3250 \mathrm{~cm}^{-1}$. NMR spectra of benchmark bisphenol-PCs are provided in Fig. S11B and S12. $\dagger$ In all cases, the results confirm (poly)carbonate linkage formation.

Interestingly, in-depth interpretation of especially ${ }^{13} \mathrm{C} \mathrm{NMR}$ data (Fig. 6A-C) as well as ${ }^{1} \mathrm{H}$ NMR data (Fig. S11†) revealed even more detailed structural information, which was used to judge monomer reactivity. Namely, as already hinted above, three separate carbonate signals (155-153 ppm; Fig. 6A) appeared for (co)polymers containing $m, p^{\prime}$-BGF monomers. Besides the tripled carbonate resonance, doubled resonances were visible in the methoxy (57-55 ppm; Fig. 6B) and the methylene (42-40 ppm; Fig. 6C) carbon regions. For methylene protons, a similar resonance doubling was detected by ${ }^{1} \mathrm{H}$ NMR (4.0-3.9 ppm, Fig. S11A $\dagger$ ), clearly reflecting the initial monomer composition. Based on these findings, a general polymer structure is proposed in Fig. 6D. The structure comprises three different types of repeating units ( $\mathbf{x}, \mathbf{y}$ and $\mathbf{z})$ - originating from at most six possible coupling combinations $\left(\mathbf{x}_{1}-\mathbf{x}_{3}, \mathbf{y}_{\mathbf{1}}, \mathbf{y}_{\mathbf{2}}\right.$ and $\left.\mathbf{z}\right)$ - each characterised by a magnetically distinct carbonate resonance. For the homopolymer of $p, p^{\prime}$-BGF, besides eight initial (monomer) resonances, only one extra (carbonate) resonance is found at $\mathbf{1 5 3 . 9} \mathrm{ppm}$. Indeed, only one type of repeating unit $\left(\mathbf{x}_{\mathbf{1}}\right)$ is possible wherein the carbonate group is linked to two aromatic hydroxyls oriented para relative to the methylene bridge ( $\mathrm{p}-\mathrm{p}$ type carbonate linkage). However, upon $m, p^{\prime}$-isomer incorporation, three distinct carbonate resonances (at 153.9, 153.8 and 153.7 ppm) appear. Namely, carbonate functionalities formed by coupling with one or two aromatic hydroxyls with meta-orientation ( $\mathrm{p}-\mathrm{m}$ and $\mathrm{m}-\mathrm{m}$ type carbonate linkage) start to arise, leading to additional repeating units (y and $\mathbf{z}$ ) for BGF-co-PCs. Unlike NMR, FT-IR spectroscopy did not allow discrimination between repeating units $\mathbf{x}, \mathbf{y}$ and/or $\mathbf{z}$, presumably due to lower spectral resolution. In addition, to further corroborate a hypothesised equal regioisomer reactivity, the expected split-
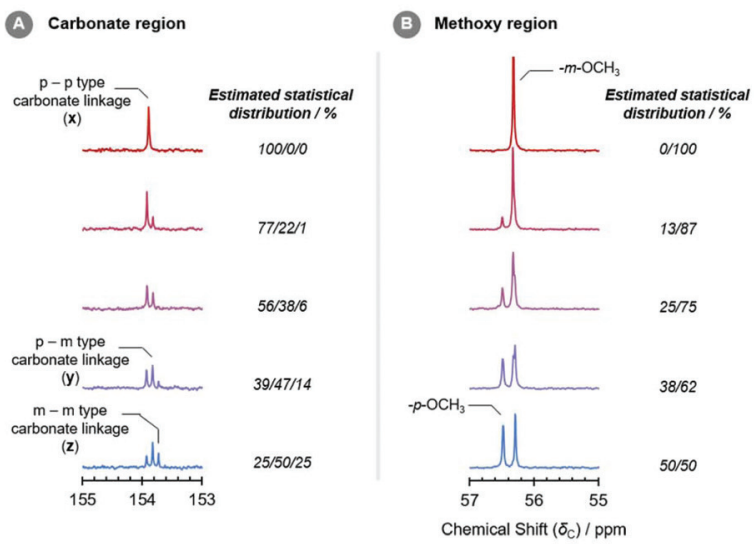

(n)
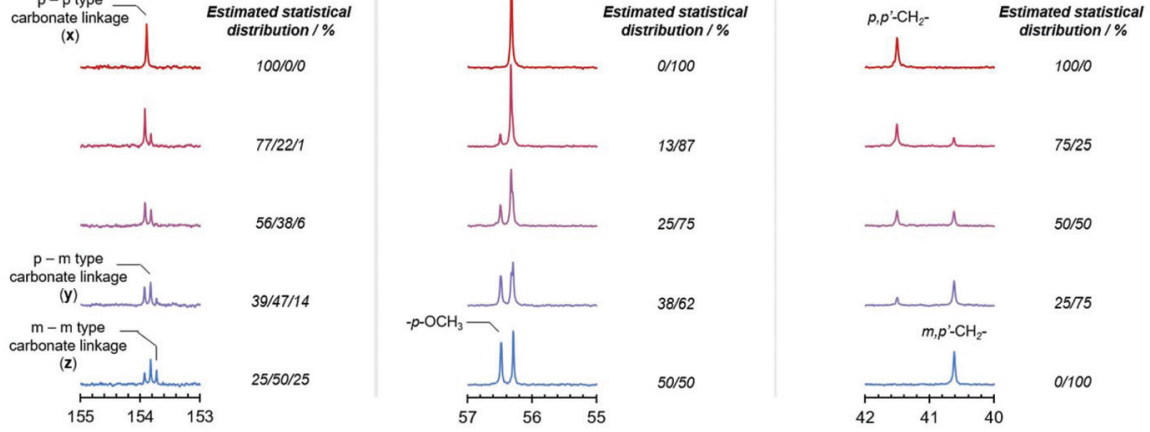

Generalised molecular structure - three possible types of magnetically non-equivalent repeating units $(\mathbf{x}, \mathbf{y}$ and $\mathbf{z})$

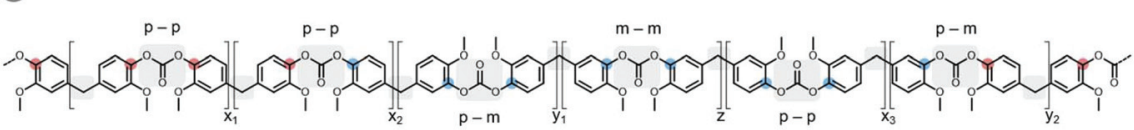

Fig. 6 Spectral enlargements of the ${ }^{13} \mathrm{C}$ NMR data of BGF-PC homo- and/or copolymers in $10 \%$ (w/w) TFA- $d / C D C l 3$ at $400 \mathrm{MHz}$ indicating the (A) carbonate (155-153 ppm), (B) methoxy (57-55 ppm), and (C) methylene carbon (42-40 ppm) regions. The full spectra are provided in Fig. S10. $\dagger$ The fraction of copolymerised $m, p^{\prime}$-BGF increases from top to bottom: $0,25,50,75$, and $100 \mathrm{wt} \%$. Statistical approximations of resonance distributions are shown (details in the ESI†). (D) Generalised molecular structure of BGF-(co-)PCs with indication of three types of magnetically non-equivalent repeating units $(\mathbf{x}, \mathbf{y}$, and $\mathbf{z})$. 
ting ratios for carbonate, methoxy and methylene moieties were estimated from calculating the theoretical statistical distributions (details in the ESI $\dagger$ ), which were shown to be in good agreement (Fig. 6A-C). This was further supported by the $M_{\mathrm{w}}$ distributions, which did not significantly differ upon incorporation of the former isomer (vide infra).

$M_{\mathrm{w}}$ distributions were estimated by GPC/SEC-UV analysis in DCM (Table 2 and Fig. 8). THF proved to be an inadequate solvent here. Whereas benchmark BPA-PC displayed an $\bar{M}_{\mathrm{w}}$ of $126 \mathrm{kDa}$ with a dispersity index $(\boxplus)$ of 3.1 , all BGF-(co-)PCs exhibited $\bar{M}_{\mathrm{w}}$ values between 20 and $25 \mathrm{kDa}$ with a $D$ ranging from 3.5-4.2. Though BGF-PCs displayed lower $M_{\mathrm{w}}$, further $M_{\mathrm{w}}$ optimisation was outside the scope of this study. Indeed, commercially suitable BPA-PCs typically have a $M_{\mathrm{w}}$ of 18-35 kDa. ${ }^{46,47}$ Therefore, a second BPA-PC reference with a $M_{\mathrm{w}}$ of similar magnitude $\left(\bar{M}_{\mathrm{w}}=16 \mathrm{kDa}, D=3.6\right)$ was made at shorter reaction time. This allowed more adequate benchmarking as thermal properties of PCs correlate with $M_{\mathrm{w}}{ }^{48}$ Strikingly, although previous reports revealed bimodal $M_{\mathrm{w}}$ distributions for 4-alkylated poly $\left(m, m^{\prime}\right.$-BGF carbonate) that were hypothesised to be related to macrocycle formation, ${ }^{34,35}$ here monomodal distributions were observed for all BGF-PCs, including homopolymeric $m, p^{\prime}$-BGF-PC. Further research should unravel if this was indeed connected to $m, m^{\prime}$-regioisomerism, or due to the type of phase-transfer catalyst used. ${ }^{49}$

Thermal characteristics were thereafter assessed by DSC and TGA under $\mathrm{N}_{2}$ (Table 2 and Fig. S14 $\dagger$ ). Benchmark BPA-PCs gave glass-transition temperatures $\left(T_{\mathrm{g}} \mathrm{s}\right)$ of $147^{\circ} \mathrm{C}$ (126 kDa) and $134{ }^{\circ} \mathrm{C}(16 \mathrm{kDa})$, while benchmark BPF-PC revealed a $T_{\mathrm{g}}$ of $114^{\circ} \mathrm{C}$. $T_{\mathrm{g}} \mathrm{s}$ of BGF-(co-)PCs were almost independent of the $m, p^{\prime}$-BGF content $\left(106-109{ }^{\circ} \mathrm{C}\right)$, except for the drop in $T_{\mathrm{g}}\left(99{ }^{\circ} \mathrm{C}\right)$ at the $50 / 50$ regioisomeric mixture. Regarding thermal stability, high and low $M_{\mathrm{w}}$ BPA-PCs displayed maximum degradation (expressed as $T_{\mathrm{d}, \max }$ ) at 498 and $474{ }^{\circ} \mathrm{C}$, respectively. All five BGF-( $\left.c o-\right)$ PCs gave quasi-identical maximum degradation at $417-419{ }^{\circ} \mathrm{C}$, irrespective of their $m, p^{\prime}$-BGF content, while benchmark BPF-PC showed a maximum mass loss at $447{ }^{\circ} \mathrm{C}$. More detailed TGA data (i.e. $T_{\mathrm{d}, 5 \%}, T_{\mathrm{d}, 10 \%}$ and $\left.T_{\mathrm{d}, 50 \%}\right)$ are provided in Table $\mathrm{S} 2 . \dagger$

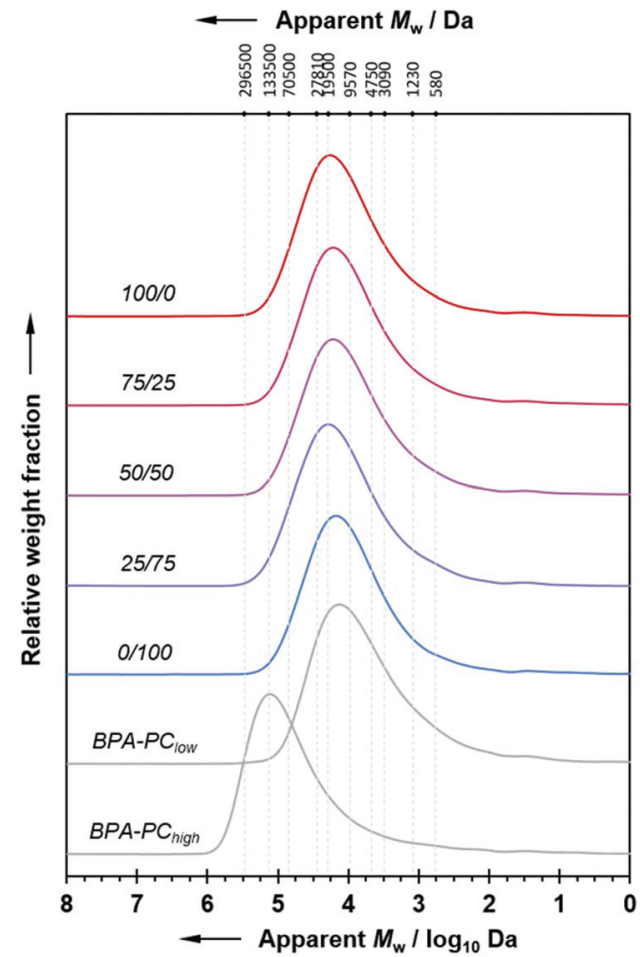

1

Fig. 8 GPC/SEC-UV traces of the as-synthesized BGF-PC homo- and/ or copolymers and BPA-PCs at $254 \mathrm{~nm}$ in DCM calibrated against polystyrene standards.

Based on DSC and TGA data, some valuable basic structure-property relationships were derived for the influence of (i) regioisomerism, (ii) o-methoxy groups, and (iii) type of bridge on the thermal characteristics (Fig. 7). The presence of $o$-methoxy groups seems to result in lower $T_{\mathrm{g}} \mathrm{s}$. For example, for BPF-PC $\left(T_{\mathrm{g}}=114^{\circ} \mathrm{C}\right)$ against $p, p^{\prime}$-BGF-PC $\left(T_{\mathrm{g}}=106^{\circ} \mathrm{C}\right)$ the $T_{\mathrm{g}}$ drops $8{ }^{\circ} \mathrm{C}$. $T_{\mathrm{g}}$ also lowers $8{ }^{\circ} \mathrm{C}$ from BPA-PC $\left(T_{\mathrm{g}}=134{ }^{\circ} \mathrm{C}\right)$ to BGA-PC $\left(T_{\mathrm{g}}=126^{\circ} \mathrm{C}\right)$. This may be attributed to the loss of segmental symmetry in monomethoxy-substituted rings (guaiacol) leading to less efficient packing, and hence more free volume. $^{50}$ The bridge type effects on the $T_{\mathrm{g}}$ are more pro-
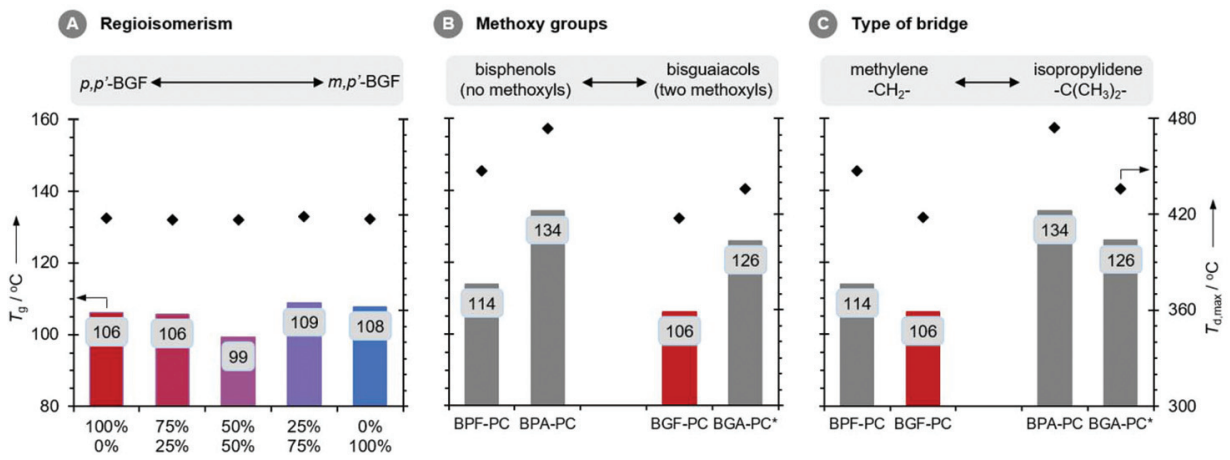

Fig. 7 Structure-property relationships between (A) regioisomerism, (B) o-methoxy content, and/or (C) type of bridge and the thermal characteristics $T_{\mathrm{g}}$ and $T_{\mathrm{d} \text {,max, }}$ in bisguaiacol-based and bisphenol-based PCs. Benchmark PCs are shown in grey. * Based on the literature, see Table 2. 
nounced, independent of the presence of $o$-methoxy groups. The isopropylidene bridges in BPA-PC $\left(T_{g}=134{ }^{\circ} \mathrm{C}\right)$ and BGA-PC $\left(T_{\mathrm{g}}=126{ }^{\circ} \mathrm{C}\right)$ yield a $20{ }^{\circ} \mathrm{C}$ higher $T_{\mathrm{g}}$ than the methylene equivalents in BPF-PC $\left(T_{\mathrm{g}}=114{ }^{\circ} \mathrm{C}\right)$ and BGF-PC $\left(T_{\mathrm{g}}=\right.$ $106{ }^{\circ} \mathrm{C}$ ), respectively. This is likely related to the level of rotational freedom of the ring segments around the central carbon bridge, which is lower for the bulkier dimethyl substitution, thereby imparting more rigidity to the polymer chains. ${ }^{51}$ Overall, thermal stability mimics the observed trends for $T_{\mathrm{g}} \mathrm{s}$ : (i) constant $T_{\mathrm{d}}$ values for the regioisomeric mixture, (ii) lower $T_{\mathrm{d}} \mathrm{S}$ for bisguaiacol-based $\left(417-436{ }^{\circ} \mathrm{C}\right)$ versus bisphenol-based PCs $\left(447-474{ }^{\circ} \mathrm{C}\right.$ ), and (iii) lower $T_{\mathrm{d}} \mathrm{s}$ for methylene $\left(418-447^{\circ} \mathrm{C}\right)$ versus isopropylidene bridges $\left(436-474{ }^{\circ} \mathrm{C}\right)$.

While strategies to obtain higher $M_{\mathrm{W}} \mathrm{S}$ are currently ongoing, here we have proven the minimal impact of $m, p^{\prime}$-BGF isomers on thermal and physicochemical properties of $p, p^{\prime}$ BGF-PCs. In other words, this implicates that significantly reduced (re)crystallisation efforts are needed to obtain PCgrade BGF.

\section{Conclusions}

In this systematic four-faceted study, the influence of $m, p^{\prime}$-bisguaiacol F ( $m, p^{\prime}$-BGF) - the main isomeric byproduct of BGF synthesis - on the safety and functionality of poly(BGF carbonate) was studied by investigating its (i) regioselective synthesis, (ii) acid-catalysed isomerisation, (iii) in vitro hER $\alpha$ oestrogenic activity, and (iv) (co)polymerization.

Starting from isovanillyl alcohol ( $m$-VA) and guaiacol, $m, p^{\prime}-$ BGF was made in an unprecedented $72 \%$ regioselectivity, which facilitated its isolation as a pure crystalline isomer. Via a similar strategy, pure $o, p^{\prime}$-BGF was selectively obtained. Interestingly, acid-catalysed isomerisation was virtually absent for the BGF isomers in guaiacol in sharp contrast to that of bisphenols in phenol. This absence enables boosting regioselectivity during acid-catalysed synthesis without the detrimental effect of isomeric scrambling. Rational catalyst design might hence lead to highly regioselective BGF formation.

Pure $m, p^{\prime}$-BGF showed substantially lower oestrogenic potency ( $\sim 426$ times lower affinity than BPA) and efficacy ( $\sim 39 \%$ of BPA's maximum induction) to in vitro transactivate $\mathrm{hER} \alpha$. It is noteworthy that the hitherto unreported beneficial effect of $o$-methoxy groups on the in vitro oestrogenic activity of the 4,4'-methylenediphenol scaffold was unambiguously proven by comparing petro-based $p, p^{\prime}$-BPF with bio-based $p, p^{\prime}$ BGF. The additional $o$-methoxy groups lowered the potency with almost two orders of magnitude, while the efficacy attained only $38 \%$ of the original $p, p^{\prime}$-BPF value. Interfacial $c o-$ polycondensation into poly $\left(p, p^{\prime}\right.$-BGF carbonate $)$ revealed an identical reactivity for $m, p^{\prime}$ - and $p, p^{\prime}$-BGF. Interestingly, it was possible to incorporate up to $25 \mathrm{wt} \%$ of $m, p^{\prime}$-BGF without affecting the polymer's thermal properties $\left(T_{\mathrm{g}}=106^{\circ} \mathrm{C}, T_{\mathrm{d}, \max }\right.$ $\left.=417{ }^{\circ} \mathrm{C}\right)$. This percentage lies well above the theoretical $m, p^{\prime}$ BGF content ( 12-19\%; without $o, p^{\prime}$-BGF) obtained during standard $p, p^{\prime}$-BGF synthesis.

\section{Experimental section}

\section{Chemicals and materials}

For a list of all used chemicals and materials as well as a more detailed description of all experimental methods and procedures, the reader is kindly referred to the ESI. $\dagger$

\section{Catalytic reactions}

For large-scale bisguaiacol production, reactions were performed in batch mode using sealed round-bottom flasks $(100 \mathrm{~mL})$ under $\mathrm{N}_{2}$ in a temperature-controlled oil bath. In a typical reaction, to vanillyl alcohol (18 mmol, $2.78 \mathrm{~g}$ ) - or one of its regioisomers - guaiacol (360 mmol, $44.69 \mathrm{~g})$ and Amberlyst ${ }^{\circledR}-15$ dry $(0.4 \mathrm{mmol}, 1.5 \mathrm{~g})$ were added, as well as a magnetic stirring bar, and stirred at $40{ }^{\circ} \mathrm{C}$ for $8 \mathrm{~h}$.

For acid-catalysed isomerisation, reactions were performed in batch mode using sealed glass vial reactors $(10 \mathrm{~mL})$ under $\mathrm{N}_{2}$ in a temperature-controlled copper heating block. In a typical reaction, to isomerically pure $p, p^{\prime}$-, $m, p^{\prime}$ - or $o, p^{\prime}$-isomer ( $\geq 99.5 \%, 2 \mathrm{mmol}, 0.52 \mathrm{~g}$ BGF or $0.40 \mathrm{~g}$ BPF), (o-methoxy) phenol (14 mmol, $1.74 \mathrm{~g}$ guaiacol or $1.32 \mathrm{~g}$ phenol), and $p$-TSA (0.12 mmol, $22.8 \mathrm{mg}$ ) were added as well as a magnetic stirring bar, and stirred at $80^{\circ} \mathrm{C}$ for the designated time.

\section{Product work-up}

Small aliquots of the reaction mixture were taken via a syringe, filtered, and used for GC-FID and GPC/SEC analysis. The remainder was filtered and excess guaiacol was removed via reduced pressure distillation $\left(90{ }^{\circ} \mathrm{C}, 7 \mathrm{mbar}\right)$, providing a product containing BGF isomers and higher molecular weight oligomers. Purification by column chromatography (35 vol\% acetone in $n$-heptane) was used to purify BGF isomers from oligomers. Hot (re)crystallisation from $n$-heptane was used to purify the main BGF isomer from the minor isomers.

$\boldsymbol{p}, \boldsymbol{p}^{\prime}$-Bisguaiacol F $\left(\boldsymbol{p}, \boldsymbol{p}^{\prime}\right.$-BGF). White solid. Yield: $1.59 \mathrm{~g}$ (34\%). M.p. $99-100{ }^{\circ} \mathrm{C}$ (polymorph I) (lit., ${ }^{29}$ 99-102) and 105-106 ${ }^{\circ} \mathrm{C}$ (polymorph II) (lit., ${ }^{5}$ 102-105). ${ }^{\mathbf{1}} \mathbf{H}$ NMR $(300 \mathrm{MHz}$, $\left.\mathrm{CDCl}_{3}, 25{ }^{\circ} \mathrm{C}, \mathrm{TMS}\right): \delta_{\mathrm{H}}=3.83\left(\mathrm{~s}, 6 \mathrm{H} ;-\mathrm{OCH}_{3}\right), 3.85(\mathrm{~s}, 2 \mathrm{H}$; $\left.-\mathrm{CH}_{2}-\right), 5.49(\mathrm{~s}, 2 \mathrm{H} ;-p-\mathrm{ArOH}), 6.65\left(\mathrm{~d},{ }^{4} J_{\mathrm{HH}}=1.7 \mathrm{~Hz}, 2 \mathrm{H} ;-O^{-}\right.$ $\mathrm{ArH}), 6.68\left(\mathrm{dd},{ }^{3} J_{\mathrm{HH}}=7.9,{ }^{4} J_{\mathrm{HH}}=1.9 \mathrm{~Hz}, 2 \mathrm{H} ;-m-\mathrm{Ar} H\right)$ and $6.84 \mathrm{ppm}\left(\mathrm{d},{ }^{3} \mathrm{~J}_{\mathrm{HH}}=7.9 \mathrm{~Hz}, 2 \mathrm{H} ;-O-\mathrm{ArH}\right) .{ }^{13} \mathrm{C} \mathbf{N M R}(100 \mathrm{MHz}$, $\mathrm{CDCl}_{3}, 25{ }^{\circ} \mathrm{C}$, TMS): $\delta_{\mathrm{C}}=146.5,143.9,133.3,121.5,114.2$, 111.3, 55.9 and $41.2 \mathrm{ppm}$. MS (70 eV, EI): $\mathrm{m} / \mathrm{z}(\%)=260$ (100) $\left[\mathrm{M}^{\cdot+}\right], 243$ (18) $\left[\mathrm{M}^{\cdot+}-{ }^{\circ} \mathrm{OH}\right], 229$ (53) $\left[\mathrm{M}^{\cdot+}-{ }^{\cdot} \mathrm{OCH}_{3}\right], 185$ (18), $137(16)\left[\mathrm{M}^{\cdot+}-{ }^{\circ} \mathrm{C}_{7} \mathrm{H}_{8} \mathrm{O}_{2}\right]$. FT-IR (KBr): $\tilde{\nu}_{\max }=3437(\mathrm{O}-\mathrm{H}), 2904$ (aliph. C-H), $1604(\mathrm{C}=\mathrm{C}), 1514,1265,1232,1036(\mathrm{C}-\mathrm{O})$ and $1018 \mathrm{~cm}^{-1}$ (C-O).

$\boldsymbol{m}, \boldsymbol{p}^{\prime}$-Bisguaiacol F ( $\boldsymbol{m}, \boldsymbol{p}^{\prime}$-BGF). White solid. Yield: $2.39 \mathrm{~g}$ (51\%). M.p. ${ }^{119-120}{ }^{\circ} \mathrm{C} .{ }^{1} \mathbf{H}$ NMR $\left(300 \mathrm{MHz}, \mathrm{CDCl}_{3}, 25{ }^{\circ} \mathrm{C}\right.$, TMS): $\delta_{\mathrm{H}}=3.81\left(\mathrm{~s}, 2 \mathrm{H} ;-\mathrm{CH}_{2}-\right), 3.83\left(\mathrm{~s}, 3 \mathrm{H} ;-m-\mathrm{OCH}_{3}\right), 3.86(\mathrm{~s}$, $3 \mathrm{H} ;-p-\mathrm{OCH}_{3}$ ), 5.47 (s, $\left.1 \mathrm{H} ;-p-\mathrm{ArOH}\right), 5.55$ (s, $\left.1 \mathrm{H} ;-m-\mathrm{ArOH}\right)$, $6.65\left(\mathrm{dd},{ }^{3} J_{\mathrm{HH}}=8.0 \mathrm{~Hz},{ }^{4} J_{\mathrm{HH}}=2.0 \mathrm{~Hz}, 1 \mathrm{H} ;-m-\mathrm{ArH}\right), 6.66(\mathrm{~d}$, $\left.{ }^{4} J_{\mathrm{HH}}=1.7 \mathrm{~Hz}, 1 \mathrm{H},-o-\mathrm{ArH}\right), 6.68\left(\mathrm{dd},{ }^{3} J_{\mathrm{HH}}=7.9 \mathrm{~Hz},{ }^{4} J_{\mathrm{HH}}=\right.$ $1.9 \mathrm{~Hz}, 1 \mathrm{H} ;-m-\mathrm{ArH}), 6.76\left(\mathrm{~d},{ }^{4} J_{\mathrm{HH}}=2.2 \mathrm{~Hz}, 1 \mathrm{H} ;-0-\mathrm{ArH}\right), 6.77$ $\left(\mathrm{d},{ }^{3} \mathrm{~J}_{\mathrm{HH}}=8.1 \mathrm{~Hz}, 1 \mathrm{H} ;-O-\mathrm{Ar} H\right)$ and $6.83 \mathrm{ppm}\left(\mathrm{d},{ }^{3} J_{\mathrm{HH}}=7.7 \mathrm{~Hz}\right.$, $1 \mathrm{H} ;-o-\mathrm{ArH}) .{ }^{13} \mathrm{C}$ NMR (100 MHz, $\left.\mathrm{CDCl}_{3}, 25{ }^{\circ} \mathrm{C}, \mathrm{TMS}\right): \delta_{\mathrm{C}}=$ 
$146.5,145.5,144.9,143.9,134.9,133.3,121.5,120.0,115.1$, 114.2, 111.4, 110.7, 56.0, 55.9 and $41.0 \mathrm{ppm}$. MS (70 eV, EI): $m / z(\%)=260(100)\left[\mathrm{M}^{\cdot+}\right], 243(18)\left[\mathrm{M}^{{ }^{+}}-{ }^{\circ} \mathrm{OH}\right], 229(47)\left[\mathrm{M}^{{ }^{+}}-\right.$ $\left.{ }^{\circ} \mathrm{OCH}_{3}\right], 185$ (19), 137 (15) $\left[\mathrm{M}^{\cdot+}-{ }^{\circ} \mathrm{C}_{7} \mathrm{H}_{8} \mathrm{O}_{2}\right]$. FT-IR $(\mathrm{KBr}): \tilde{\nu}_{\max }=$ $3433(\mathrm{O}-\mathrm{H}), 2902$ (aliph. $\mathrm{C}-\mathrm{H}), 1610(\mathrm{C}=\mathrm{C}), 1587(\mathrm{C}=\mathrm{C}), 1512$, $1257,1234,1032(\mathrm{C}-\mathrm{O})$ and $1020 \mathrm{~cm}^{-1}(\mathrm{C}-\mathrm{O})$.

$\boldsymbol{o}, \boldsymbol{p}^{\prime}$-Bisguaiacol F $\left(\boldsymbol{o}, \boldsymbol{p}^{\prime}\right.$-BGF). White solid. Yield: $1.41 \mathrm{~g}$ (30\%). M.p. ${ }^{103-105}{ }^{\circ} \mathrm{C} .{ }^{\mathbf{1}} \mathbf{H}$ NMR $\left(300 \mathrm{MHz} \mathrm{CDCl}_{3}, 25{ }^{\circ} \mathrm{C}\right.$, TMS): $\delta_{\mathrm{H}}=3.84\left(\mathrm{~s}, 3 \mathrm{H} ;-m-\mathrm{OCH}_{3}\right), 3.88\left(\mathrm{~s}, 3 \mathrm{H} ;-m-\mathrm{OCH}_{3}\right), 3.92$ (s, 2H;- $\left.\mathrm{CH}_{2}-\right), 5.45(\mathrm{~s}, 1 \mathrm{H} ;-p-\mathrm{ArOH}), 5.73(\mathrm{~s}, 1 \mathrm{H} ;-o-\mathrm{ArOH})$, 6.67-6.81 ppm (m, 5H; -ArH), $6.82\left(\mathrm{~d},{ }^{3} J_{\mathrm{HH}}=8.0 \mathrm{~Hz}, 1 \mathrm{H} ;-O_{-}\right.$ $\mathrm{ArH}) .{ }^{13} \mathrm{C}$ NMR (100 MHz, $\left.\mathrm{CDCl}_{3}, 25{ }^{\circ} \mathrm{C}, \mathrm{TMS}\right): \delta_{\mathrm{C}}=146.52$, $146.48,143.9,143.5,132.8,127.5,122.7,121.6,119.5,114.3$, 111.7, 108.8, 56.1, 55.9 and $35.2 \mathrm{ppm}$. MS (70 eV, EI): $\mathrm{m} / z(\%)=$ 260 (100) $\left[\mathrm{M}^{\cdot+}\right], 227$ (13), 137 (29) $\left[\mathrm{M}^{\cdot+}-{ }^{\circ} \mathrm{C}_{7} \mathrm{H}_{8} \mathrm{O}_{2}\right], 136$ (21), $124(45)\left[\mathrm{M}^{\cdot+}{ }^{-} \mathrm{C}_{8} \mathrm{H}_{8} \mathrm{O}_{2}\right]$. FT-IR (KBr): $\tilde{\nu}_{\max }=3450(\mathrm{O}-\mathrm{H}), 2939$ (aliph. $\mathrm{C}-\mathrm{H}), 1612(\mathrm{C}=\mathrm{C}), 1591(\mathrm{C}=\mathrm{C}), 1516,1471,1439,1284$, 1265, 1240, 1221, 1064 (C-O), 1032 (C-O) and $746 \mathrm{~cm}^{-1}$ (orthosubstitution).

Full 1D $\left({ }^{1} \mathrm{H},{ }^{13} \mathrm{C},{ }^{13} \mathrm{C}-\mathrm{DEPT}-135^{\circ}\right)$ and $2 \mathrm{D}{ }^{1} \mathrm{H},{ }^{13} \mathrm{C} \mathrm{HMBC}$ NMR, MS and FT-IR spectra are provided in the ESI. $\dagger$ Also MS data collected from other minor regioisomers, such as $m, p^{\prime}$ *-BGF (from vanillyl alcohol), $m, m^{\prime}-, o, m^{\prime}$ - and $m, m^{*}$-BGF (from isovanillyl alcohol) and $o, m^{\prime}-, o, o^{\prime}$ - and $o, m^{\prime *}$-BGF (from ortho-vanillyl alcohol), are reported in the ESI. $\dagger$

\section{Quantification}

Gas chromatography (GC) was performed on a HewlettPackard (HP) 5890 with a CP-SIL 5CB WCOT fused silica column (30 $\mathrm{m} \times 0.32 \mathrm{~mm}$, film thickness of $1.0 \mu \mathrm{m})$, equipped with an FID detector $\left(310^{\circ} \mathrm{C}\right)$ and Agilent ChemStation software. The injection port and initial oven temperatures were 300 and $35{ }^{\circ} \mathrm{C}$, respectively. This temperature was held for $4 \mathrm{~min}$, increased to $300{ }^{\circ} \mathrm{C}$ at $10{ }^{\circ} \mathrm{C} \mathrm{min}^{-1}$, and held for $40 \mathrm{~min}$. Prior to GC-FID analysis, samples were derivatised via trimethylsilylation with $N$-methyl- $N$-(trimethylsilyl)trifluoroacetamide (MSTFA). In a typical sample preparation, an aliquot of the reaction mixture (50 $\mathrm{mg})$, together with creosol $(10 \mathrm{mg})$ as an external standard, was accurately weighed in a glass vial and homogeneously mixed with pyridine $(100 \mu \mathrm{L})$ and MSTFA $(250 \mu \mathrm{L})$. To guarantee complete derivatisation, the samples were heated at $80{ }^{\circ} \mathrm{C}$ for $15 \mathrm{~min}$ and subsequently diluted with ACN $(1 \mathrm{~mL})$. One $\mu \mathrm{L}$ of the sample was injected at a split ratio of 1 : 100. This GC-FID methodology allows obtaining separate signals for all BGF regioisomers. Quantification was performed by calibration with the pure (isolated) product against the external standard.

\section{In vitro hER $\alpha$ activity}

The oestrogenic activity of the bisguaiacol and bisphenol analogues was determined as reported previously by Witters et al. (2010) with slight modifications. ${ }^{52}$

Briefly, hER $\alpha$ transcriptional activity is determined using MCF-7 cells that are stably transfected with hER $\alpha$ (MELN-hER $\alpha$ cell line). Activity is measured in relative light units (RLU) and presented as induction of ER activation relative to luciferase induction by the vehicle control (set as 100\%). Results from three replicate cellular exposures for each test condition were averaged \pm standard deviation (SD) using Graphpad Prism software (version $7.03,2017$ ) with calculation of $\mathrm{EC}_{50}$ and $E_{\max }$ values determined by fitting a four-parameter sigmoidal doseresponse curve ( $c f$. Hill equation). To obtain $\mathrm{EC}_{50}$ values for partial dose-response curves, the fit was constrained at the top and/or bottom value. For a detailed description of the complete experimental procedure, the reader is kindly referred to the ESI. $\dagger$

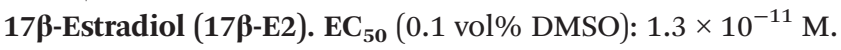
$\log _{10}$ REP (vs. 17 $\beta$-E2): +2.00. $\boldsymbol{E}_{\max }\left(0.1 \mathrm{vol} \%\right.$ DMSO, $\mathrm{VC}_{\mathrm{DMSO}}=$ 100\%): 603\%. REE (vs. 17 $\beta$-E2): 100\%.

$\boldsymbol{p}, \boldsymbol{p}^{\prime}$-Bisphenol A (p,p'-BPA). $\mathbf{E C}_{50}$ (0.1 vol\% DMSO): $6.6 \times$ $10^{-7}$ M. $\log _{10}$ REP (vs. 17 $\beta$-E2): -2.19. $\boldsymbol{E}_{\max }$ (0.1 vol\% DMSO, $\left.\mathrm{VC}_{\mathrm{DMSO}}=100 \%\right): 577 \%$. REE (vs. $\left.17 \beta-\mathrm{E} 2\right): 96 \%$.

$\boldsymbol{p}, \boldsymbol{p}^{\prime}$-Bisphenol F ( $\boldsymbol{p}, \boldsymbol{p}^{\prime}$-BPF). $\mathbf{E C}_{50}$ (0.1 vol\% DMSO): $1.4 \times$ $10^{-6}$ M. $\log _{10}$ REP (vs. 17 $\beta$-E2): -3.02. $E_{\max }(0.1$ vol\% DMSO, $\left.\mathrm{VC}_{\mathrm{DMSO}}=100 \%\right): 760 \%$. REE (vs. $\left.17 \beta-\mathrm{E} 2\right): 126 \%$.

$\boldsymbol{p}, \boldsymbol{p}^{\prime}$-Bisguaiacol F ( $\boldsymbol{p}, \boldsymbol{p}^{\prime}$-BGF). $\mathbf{E C}_{50}$ (0.1 vol\% DMSO): $9.4 \times$ $10^{-5}$ M. $\log _{10}$ REP (vs. 17 $\beta$-E2): -4.85 . $E_{\max }$ (0.1 vol\% DMSO, $\left.\mathrm{VC}_{\mathrm{DMSO}}=100 \%\right): 289 \% . \mathbf{R E E}(v s .17 \beta-\mathrm{E} 2): 48 \%$.

$\boldsymbol{m}, \boldsymbol{p}^{\prime}$-Bisguaiacol F ( $\boldsymbol{m}, \boldsymbol{p}^{\prime}$-BGF). EC $\mathbf{E C}_{50}(0.1$ vol\% DMSO): $8.7 \times$ $10^{-5}$ M. $\log _{10}$ REP (vs. $\left.17 \beta-\mathrm{E} 2\right):-4.82 . E_{\max }$ (0.1 vol\% DMSO, $\left.\mathrm{VC}_{\mathrm{DMSO}}=100 \%\right): 225 \%$. REE (vs. $\left.17 \beta-\mathrm{E} 2\right): 37 \%$.

\section{(Co)polymerisation}

Polycarbonates were prepared on a gram scale via interfacial polymerisation with triphosgene. CAREFUL: Safety rules and precautions that are at least as strict as those for phosgene must be applied. In a two-necked round-bottom flask $(25 \mathrm{~mL})$ bisphenols or (mixtures of) bisguaiacols (2.2 $\mathrm{mmol}$ in total) were deprotonated in an aqueous solution of $\mathrm{NaOH}(7.5 \mathrm{mmol}$ in $4 \mathrm{~mL}$ ). After complete dissolution, a separate solution of triphosgene (1.3 mmol, $0.375 \mathrm{~g}$ ) in DCM ( $4 \mathrm{~mL}$ ) was added and stirred for $30 \mathrm{~min}$ at $25{ }^{\circ} \mathrm{C}$. TEA $(6 \mu \mathrm{L})$ and $50 \%(\mathrm{w} / \mathrm{v})$ aqueous tetrabutylammonium chloride $(3 \mu \mathrm{L})$ were added and the mixture was vigorously stirred for $5 \mathrm{~h}$ at $25{ }^{\circ} \mathrm{C}$. After reaction, the aqueous and organic phases were separated. The organic phase was washed with distilled water $(3 \times 50 \mathrm{~mL})$, neutralised with $\mathrm{HCl}$, and precipitated in hot water $\left(100 \mathrm{~mL}, 60^{\circ} \mathrm{C}\right)$. The polymer was collected by filtration, pulverised and dried in vacuo $\left(80^{\circ} \mathrm{C}, \sim 1 \mathrm{mbar}\right)$. Polymer yield is calculated from the theoretical molar mass of the repeating units, being 254.28, 226.22 and $286.28 \mathrm{~g} \mathrm{~mol}^{-1}$ for BPA-PC, BPF-PC and BGF-PC, respectively, assuming that the total amount of end-groups is negleglible to the total polymer weight.

Poly $\left(\boldsymbol{p}, \boldsymbol{p}^{\prime}\right.$-BPA carbonate) (BPA-PC). White solid. Yield: $0.45 \mathrm{~g}$ (81\%). ${ }^{1} \mathbf{H}$ NMR $\left(300 \mathrm{MHz}, \mathrm{CDCl}_{3}, 25{ }^{\circ} \mathrm{C}, \mathrm{TMS}\right): \delta_{\mathrm{H}}=1.68(\mathrm{~s}$, $\left.6 \mathrm{H} ;-\mathrm{CH}_{3}\right), 7.21\left(\mathrm{dd},{ }^{3} J_{\mathrm{HH}}=6.7 \mathrm{~Hz},{ }^{4} J_{\mathrm{HH}}=2.1 \mathrm{~Hz}, 2 \mathrm{H} ;-m-\mathrm{ArH}\right)$ and $7.25 \mathrm{ppm}\left(\mathrm{dd},{ }^{3} J_{\mathrm{HH}}=6.6 \mathrm{~Hz},{ }^{4} J_{\mathrm{HH}}=2.2 \mathrm{~Hz} 2 \mathrm{H} ;-O-\operatorname{Ar} H\right)$. ${ }^{13} \mathrm{C}$ NMR (100 MHz, $\mathrm{CDCl}_{3}, 25{ }^{\circ} \mathrm{C}$, TMS): $\delta_{\mathrm{C}}=, 149.0,148.3$, 127.9, 120.3, 42.6 and 30.9 ppm. FT-IR (KBr): $\tilde{\nu}_{\max }=1774 \mathrm{~cm}^{-1}$ (C=O stretch). $\boldsymbol{M}_{\mathbf{w}}\left(\mathrm{GPC}, \mathrm{DCM}, 30^{\circ} \mathrm{C}, 254 \mathrm{~nm}, \mathrm{PS}\right): \bar{M}_{\mathrm{n}}=4.458$ and $\bar{M}_{\mathrm{w}}=15.902 \mathrm{~g} \mathrm{~mol}^{-1}, D=3.6$. 
Poly $\left(\boldsymbol{p}, \boldsymbol{p}^{\prime}\right.$-BPF carbonate) (BPF-PC). Off-white solid. Yield: $0.37 \mathrm{~g}(74 \%) .{ }^{1} \mathbf{H}$ NMR $\left(300 \mathrm{MHz}, 10 \%(\mathrm{w} / \mathrm{w})\right.$ TFA- $d / \mathrm{CDCl}_{3}$, $\left.25{ }^{\circ} \mathrm{C}, \mathrm{TMS}\right): \delta_{\mathrm{H}}=4.00\left(\mathrm{~s}, 2 \mathrm{H} ;-\mathrm{CH}_{2}-\right), 7.17\left(\mathrm{dd},{ }^{3} J_{\mathrm{HH}}=6.5 \mathrm{~Hz}\right.$, $\left.{ }^{4} J_{\mathrm{HH}}=2.3 \mathrm{~Hz}, 2 \mathrm{H} ;-m-\mathrm{Ar} H\right)$ and $7.22 \mathrm{ppm}\left(\mathrm{dd},{ }^{3} J_{\mathrm{HH}}=6.5 \mathrm{~Hz}\right.$, $\left.{ }^{4} J_{\mathrm{HH}}=2.3 \mathrm{~Hz} 2 \mathrm{H} ;-O-\mathrm{ArH}\right) .{ }^{13} \mathrm{C}$ NMR $(100 \mathrm{MHz}, 10 \% \mathrm{w} / \mathrm{w}$ TFA$\left.d / \mathrm{CDCl}_{3}, 25{ }^{\circ} \mathrm{C}, \mathrm{TMS}\right): \delta_{\mathrm{C}}=154.2,149.3,139.5,130.3,121.1$ and $40.6 \mathrm{ppm}$. FT-IR (KBr): $\tilde{\nu}_{\max }=1772 \mathrm{~cm}^{-1}$ (C=O stretch).

Poly $\left(\boldsymbol{p}, \boldsymbol{p}^{\prime}\right.$-BGF carbonate) ( $\boldsymbol{p}, \boldsymbol{p}^{\prime}$-BGF-PC). Light-yellow solid. Yield: $0.56 \mathrm{~g}(89 \%) .{ }^{1} \mathbf{H}$ NMR $(300 \mathrm{MHz}, 10 \%(\mathrm{w} / \mathrm{w})$ TFA- $d /$ $\left.\mathrm{CDCl}_{3}, 25{ }^{\circ} \mathrm{C}, \mathrm{TMS}\right): \delta_{\mathrm{H}}=3.86\left(\mathrm{~s}, 6 \mathrm{H} ;-\mathrm{OCH}_{3}\right), 3.98(\mathrm{~s}, 2 \mathrm{H}$; $\left.-\mathrm{CH}_{2}-\right), 6.79\left(\mathrm{dd},{ }^{3} J_{\mathrm{HH}}=8.2,{ }^{4} J_{\mathrm{HH}}=1.6 \mathrm{~Hz}, 2 \mathrm{H} ;-m-\mathrm{Ar} H\right), 6.82$ $\left(\mathrm{d},{ }^{4} J_{\mathrm{HH}}=1.5 \mathrm{~Hz}, 2 \mathrm{H} ;-O-\operatorname{Ar} H\right)$ and $7.14 \mathrm{ppm}\left(\mathrm{d},{ }^{3} J_{\mathrm{HH}}=8.1 \mathrm{~Hz}\right.$, $2 \mathrm{H} ;-o-\mathrm{Ar} H) .{ }^{13} \mathrm{C}$ NMR $\left(100 \mathrm{MHz}, 10 \% \mathrm{w} / \mathrm{w}\right.$ TFA- $d / \mathrm{CDCl}_{3}, 25{ }^{\circ} \mathrm{C}$, TMS): $\delta_{\mathrm{C}}=153.9,150.7,140.7,138.4,122.2,121.7,113.9,56.3$ and $41.5 \mathrm{ppm}$. FT-IR $(\mathrm{KBr}): \tilde{\nu}_{\max }=1780 \mathrm{~cm}^{-1}(\mathrm{C}=\mathrm{O}$ stretch$)$. $\boldsymbol{M}_{\mathrm{w}}\left(\mathrm{GPC}, \mathrm{DCM}, 30{ }^{\circ} \mathrm{C}, 254 \mathrm{~nm}, \mathrm{PS}\right): \bar{M}_{\mathrm{n}}=6.069$ and $\bar{M}_{\mathrm{w}}=$ $23.298 \mathrm{~g} \mathrm{~mol}^{-1}, D=3.8$.

Poly $\left(\boldsymbol{m}, \boldsymbol{p}^{\prime}\right.$-BGF carbonate) ( $\boldsymbol{m}, \boldsymbol{p}$-BGF-PC). Light-yellow solid. Yield: $0.55 \mathrm{~g}$ (88\%). ${ }^{1} \mathbf{H}$ NMR $(300 \mathrm{MHz}, 10 \%(\mathrm{w} / \mathrm{w})$ TFA- $d /$ $\left.\mathrm{CDCl}_{3}, 25{ }^{\circ} \mathrm{C}, \mathrm{TMS}\right): \delta_{\mathrm{H}}=3.83\left(\mathrm{~s}, 3 \mathrm{H} ;-m-\mathrm{OCH}_{3}\right), 3.84(\mathrm{~s}, 3 \mathrm{H} ;-$ $\left.m-\mathrm{OCH}_{3}\right), 3.87\left(\mathrm{~s}, 3 \mathrm{H} ;-p-\mathrm{OCH}_{3}\right), 3.89\left(\mathrm{~s}, 3 \mathrm{H} ;-p-\mathrm{OCH}_{3}\right), 3.93(\mathrm{~s}$, $\left.2 \mathrm{H} ;-\mathrm{CH}_{2}-\right), 6.78\left(\mathrm{dd},{ }^{3} J_{\mathrm{HH}}=8.2,{ }^{4} J_{\mathrm{HH}}=1.8 \mathrm{~Hz}, 1 \mathrm{H} ;-O-\mathrm{Ar} H\right)$, $6.81\left(\mathrm{~d},{ }^{4} J_{\mathrm{HH}}=1.7 \mathrm{~Hz}, 1 \mathrm{H} ;-o-\mathrm{ArH}\right), 6.95\left(\mathrm{~d},{ }^{3} J_{\mathrm{HH}}=8.9 \mathrm{~Hz}, 1 \mathrm{H} ;-\right.$ $m-\operatorname{Ar} H), 7.01-7.08(\mathrm{~m}, 2 \mathrm{H})$ and $7.13\left(\mathrm{~d}, 1 \mathrm{H},{ }^{3} \mathrm{~J}_{\mathrm{HH}}=8.2 \mathrm{~Hz} ;-m^{-}\right.$ $\operatorname{Ar} H)$ ppm. ${ }^{13} \mathrm{C}$ NMR $\left(100 \mathrm{MHz}, 10 \% \mathrm{w} / \mathrm{w}\right.$ TFA- $d / \mathrm{CDCl}_{3}, 25{ }^{\circ} \mathrm{C}$, TMS): $\delta_{\mathrm{C}}=153.9,153.8,153.7,150.7,149.2,141.0,139.8$, 138.3, 133.9, 128.3, 122.8, 122.2, 121.7, 113.9, 113.5, 56.5, 56.3 and $40.6 \mathrm{ppm}$. FT-IR $(\mathrm{KBr}): \tilde{\nu}_{\max }=1782 \mathrm{~cm}^{-1}(\mathrm{C}=\mathrm{O}$ stretch$)$. $\boldsymbol{M}_{\mathbf{w}}\left(\mathrm{GPC}, \mathrm{DCM}, 30^{\circ} \mathrm{C}, 254 \mathrm{~nm}, \mathrm{PS}\right): \bar{M}_{\mathrm{n}}=5.744$ and $\bar{M}_{\mathrm{w}}=$ $20.044 \mathrm{~g} \mathrm{~mol}^{-1}, D=3.5$.

\section{Characterisation of bisguaiacols and polycarbonates}

Liquid-phase ${ }^{1} \mathrm{H}$ and ${ }^{13} \mathrm{C}$ NMR spectra were acquired on Bruker Avance instruments ( 300 and $400 \mathrm{MHz}$ ) with automated samplers. Chemical shifts $(\delta)$ are reported in parts per million (ppm) referenced to tetramethylsilane $\left({ }^{1} \mathrm{H}\right)$ or the internal NMR solvent signals $\left({ }^{13} \mathrm{C}\right)$. In a typical sample preparation, a dried sample ( $\pm 3 \mathrm{mg}$ for ${ }^{1} \mathrm{H}$ and $\pm 30 \mathrm{mg}$ for ${ }^{13} \mathrm{C}$ ) is homogeneously dissolved in $650-750 \mu \mathrm{L}$ in $\mathrm{CDCl}_{3}$ (for bisguaiacols and BPA-PC) or $10 \%(\mathrm{w} / \mathrm{w})$ TFA- $d / \mathrm{CDCl}_{3}$ (for other PCs), and transferred to a NMR tube. FT-IR spectra of dried KBr pellets, pre-mixed with a pure product (1 wt\%), were recorded in vacuo on a Bruker IFS $66 \mathrm{v} / \mathrm{S}$ instrument. PXRD patterns were recorded on powdered samples on a STOE Stadi P Combi diffractometer with an image plate position sensitive detector (IP-PSD) in the region $2 \theta=5$ to $60^{\circ}\left(\Delta 2 \theta=0.03^{\circ}\right)$ and a scan of maximum $1200 \mathrm{~s}$. The measurements were performed in transmission mode at room temperature using CuK $\alpha 1$ radiation $(\lambda=$ $1.54056 \AA$ ) selected by means of a Ge(111) monochromator. GPC/SEC analysis of bisguaiacols was performed on a Waters e2695 Separations Module with a pre-column and a Varian M-Gel column ( $3 \mu \mathrm{m}$, mixed), equipped with a Waters 2988 Photodiode array detector (at $280 \mathrm{~nm}$ ), Empower software and using THF as the mobile phase $\left(1 \mathrm{~mL} \mathrm{~min}^{-1}\right)$ at $40{ }^{\circ} \mathrm{C}$. GPC/ SEC analysis of polymers was performed on a Shimadzu system (LC-10ADvp pump unit, CTO-10Avp column oven and
SCL-10Avp gradient controller) with an Agilent PLgel $5 \mu \mathrm{m}$ MIXED-D $(300 \times 7.5 \mathrm{~mm})$ column, equipped with a Shimadzu SDP-10Avp UV-VIS detector (at $254 \mathrm{~nm}$ ), using DCM as a mobile phase $\left(1 \mathrm{~mL} \mathrm{~min}{ }^{-1}\right)$ at $30^{\circ} \mathrm{C}$. Polymers were dissolved in DCM (1-2 $\mathrm{mg} \mathrm{mL}^{-1}$ ) and left to stand $24 \mathrm{~h}$ at room temperature prior to being measured. Before measurement, the solutions were consecutively filtered over two Millex® FH filters (PTFE, 0.45 and $0.2 \mu \mathrm{m}$ ). Solutions were injected with a Fortuna ${ }^{\circledR}$ Optima glass syringe $(0.1 \mathrm{~mL})$. The system was calibrated with low disperse polystyrene (PS) standards, and $M_{\mathrm{w}} \mathrm{S}$ $\left(\bar{M}_{\mathrm{n}}\right.$ and $\left.\bar{M}_{\mathrm{w}}\right)$ are reported as PS equivalents. TGA was performed using a TA Instrument TGA Q500 under a $\mathrm{N}_{2}$ or ambient atmosphere (at $20 \mathrm{~mL} \mathrm{~min}^{-1}$ ). Typically, about $10 \mathrm{mg}$ of the dry sample was heated to $600{ }^{\circ} \mathrm{C}$ at $10{ }^{\circ} \mathrm{C} \mathrm{min}^{-1}$ and kept isothermal for $15 \mathrm{~min}$. Melting points $\left(T_{\mathrm{m}}\right)$ were determined using glass capillaries in a Stuart Scientific SMP3 melting point apparatus and confirmed by DSC. DSC experiments were performed on TA Instruments DSC Q200 by cycling between (i) $20-135{ }^{\circ} \mathrm{C}$ for bisguaiacols, (ii) $20-250{ }^{\circ} \mathrm{C}$ for bisguaiacol-based polymers and (iii) $20-300{ }^{\circ} \mathrm{C}$ for bisphenol-based polymers at $10{ }^{\circ} \mathrm{C} \mathrm{min}^{-1}$ under a $\mathrm{N}_{2}$ atmosphere $\left(50 \mathrm{~mL} \mathrm{~min}{ }^{-1}\right)$. In a typical sample preparation, about 3-8 $\mathrm{mg}$ of the sample was precisely weighed in aluminum pans and covered with (non-hermetic) lids.

\section{Conflicts of interest}

There are no conflicts of interest to declare.

\section{Acknowledgements}

This work was performed in the framework of the cross-border EU Interreg Flanders-The Netherlands project BIO-HArT as well as the FWO-SBO project BioWood, and was supported by the Catalisti SBO project ARBOREF (S.-F. K. and L. T.) and the EOS Excellence of Science program BioFact (D. R.). T. R. acknowledges postdoctoral research funding from the $\mathrm{KU}$ Leuven Internal Funds (PDM). The authors kindly thank Karel Duerinckx for the NMR measurements, and An Jacobs for MELN testing. The authors acknowledge Dr Patrick Balaguer (INSERM) who kindly provided the MELN cells.

\section{Notes and references}

1 Y. Zhu, C. Romain and C. K. Williams, Nature, 2016, 540, 354-362.

2 W. Schutyser, T. Renders, S. Van den Bosch, S.-F. Koelewijn, G. T. Beckham and B. F. Sels, Chem. Soc. Rev., 2018, 47, 852-908.

3 S. Crossley, J. Faria, M. Shen and D. E. Resasco, Science, 2010, 327, 68-72.

4 M. Fache, B. Boutevin and S. Caillol, ACS Sustainable Chem. Eng., 2015, 4, 35-46. 
5 E. D. Hernandez, A. W. Bassett, J. M. Sadler, J. J. La Scala and J. F. Stanzione III, ACS Sustainable Chem. Eng., 2016, 4, 4328-4339.

6 J. R. Mauck, S. K. Yadav, J. M. Sadler, J. J. La Scala, G. R. Palmese, K. M. Schmalbach and J. F. Stanzione III, Macromol. Chem. Phys., 2017, 218, 1700013.

7 J. R. Mauck, A. W. Bassett, J. M. Sadler, J. J. La Scala, E. Napadensky, K. H. Reno and J. F. Stanzione III, J. Biobased Mater. Bioenergy, 2018, 12, 471-476.

8 S. Curia, A. Biundo, I. Fischer, V. Braunschmid, G. M. Gübitz and J. F. Stanzione, ChemSusChem, 2018, 11, 2529-2539.

9 J. B. Zimmerman and P. T. Anastas, Science, 2015, 347, 1198-1199.

10 R. Rochester Johanna and L. Bolden Ashley, Environ. Health Perspect., 2015, 123, 643-650.

11 A. T. Szafran, F. Stossi, M. G. Mancini, C. L. Walker and M. A. Mancini, PLoS One, 2017, 12, e0180141.

12 L. Pilato, in Phenolic resins: a century of progress, ed. L. Pilato, Springer, Berlin, 1st edn, 2010, ch. 4, p. 54.

13 J. De Jong and F. Dethmers, Recl. Trav. Chim. Pays-Bas, 1965, 84, 460-464.

14 K. K. Sun, US Pat, 4052466A, 1977.

15 B. W. Jackson, US Pat, 0114716A1, 2003.

16 A. Gardziella, L. A. Pilato and A. Knop, in Phenolic Resins: Chemistry, Applications, Standardization, Safety and Ecology, ed. A. Gardziella, L. A. Pilato and A. Knop, Springer, Berlin, 2nd edn, 2000, ch. 2, pp. 37-38.

17 S. K. Jana, T. Kugita and S. Namba, Appl. Catal., A, 2004, 266, 245-250.

18 A. G. Farnham and F. P. Klosek, US Pat, 2812364A, 1957.

19 M. R. Ort, US Pat, 4400554, 1983.

20 A. P. Singh and S. Dagade, US Pat, 6492566B1, 2002.

21 A. Garade, V. Kshirsagar and C. Rode, Appl. Catal., A, 2009, 354, 176-182.

22 D. Wang, Z. He, Z. Wu, Y. Tan, Y. Li and Y. Liu, Chin. J. Chem. Eng., 2016, 24, 1166-1170.

23 Y. Kosaka and K. B. Sinclair, Bisphenol-A from phenol and acetone with an ion exchange resin catalyst - Union Carbide Technology, 1982.

24 H. H. Szmant, Organic building blocks of the chemical industry, Wiley, 1989.

25 F. Cavani, M. Corrado and R. Mezzogori, J. Mol. Catal. A: Chem., 2002, 182, 447-453.

26 K. H. Reno, J. F. Stanzione III, R. P. Wool, J. M. Sadler, J. J. Lascala and E. D. Hernandez, US Pat, 0210689A1, 2017.

27 K. H. Nicastro, C. J. Kloxin and T. H. Epps, ACS Sustainable Chem. Eng., 2018, 6, 14812-14819.

28 A. P. Pleshkova, M. N. Uspenskaya and S. V. Volkovitch, Org. Mass Spectrom., 1994, 29, 26-29.

29 D. R. Dimmel, D. Shepard and T. A. Brown, J. Wood Chem. Technol., 1981, 1, 123-146.
30 U. Rudolph and C. Wulff, US Pat, 5015784, 1991.

31 F. Oi, N. Yanase and M. Yamamoto, 2005.

32 J. R. Campbell, US Pat, 4156790, 1979.

33 S. Van de Vyver, S. Helsen, J. Geboers, F. Yu, J. Thomas, M. Smet, W. Dehaen, Y. Román-Leshkov, I. Hermans and B. F. Sels, ACS Catal., 2012, 2, 2700-2704.

34 S.-F. Koelewijn, S. Van den Bosch, T. Renders, W. Schutyser, B. Lagrain, M. Smet, J. Thomas, W. Dehaen, P. Van Puyvelde, H. Witters and B. F. Sels, Green Chem., 2017, 19, 2561-2570.

35 S.-F. Koelewijn, C. Cooreman, T. Renders, C. Andecochea Saiz, S. Van den Bosch, W. Schutyser, W. De Leger, M. Smet, P. Van Puyvelde, H. Witters, B. Van der Bruggen and B. F. Sels, Green Chem., 2018, 20, 1050-1058.

36 G. Chandra, E. J. Nesakumar, V. R. G. Bhotla, S. G. Shetty, J. Mahood, R. R. Gallucci, J. H. Kamps and M. S. Kumar, US Pat, 9120893B1, 2015.

37 E. Palomino, Crit. Rev. Biochem. Mol. Biol., 1999, 34, 387398.

38 Y. Peng, K. H. Nicastro, T. H. Epps and C. Wu, J. Agric. Food Chem., 2018, 66, 11775-11783.

39 J. Hitce, M. Crutizat, C. Bourdon, A. Vivès, X. Marat and M. Dalko-Csiba, Green Chem., 2015, 17, 3756-3761.

40 A. Trita, L. Over, J. Pollini, S. Baader, S. Riegsinger, M. Meier and L. Gooßen, Green Chem., 2017, 19, 30513060.

41 Chemical Economics Handbook: Bisphenol A, IHS Markit, 2018, https://ihsmarkit.com/products/bisphenol-chemicaleconomics-handbook.html (accessed June 2019).

42 S. Fukuoka, M. Kawamura, K. Komiya, M. Tojo, H. Hachiya, K. Hasegawa, M. Aminaka, H. Okamoto, I. Fukawa and S. Konno, Green Chem., 2003, 5, 497-507.

43 S. Fukuoka, I. Fukawa, T. Adachi, H. Fujita, N. Sugiyama and T. Sawa, Org. Process Res. Dev., 2019, 23, 145-169.

44 C. Kim and D. Paul, Macromolecules, 1992, 25, 30973105.

45 R. Hariharan and A. Pinkus, Polym. Bull., 1993, 30, 91-95.

46 D. Freitag, G. Fengler and L. Morbitzer, Angew. Chem., Int. Ed. Engl., 1991, 30, 1598-1610.

47 G. Abts, T. Eckel and R. Wehrmann, in Ullmann's Encyclopedia of Industrial Chemistry, 2014.

48 G. A. Adam, J. N. Hay, I. W. Parsons and R. N. Haward, Polymer, 1976, 17, 51-57.

49 H. R. Kricheldorf, S. Böhme, G. Schwarz and C.-L. Schultz, Macromolecules, 2004, 37, 1742-1748.

50 A. Yee and S. Smith, Macromolecules, 1981, 14, 54-64.

51 A. Perepelkin and P. Kozlov, Polym. Sci., Ser. A, 1966, 8, 5762.

52 H. Witters, A. Freyberger, K. Smits, C. Vangenechten, W. Lofink, M. Weimer, S. Bremer, P. H. J. Ahr and P. Berckmans, Reprod. Toxicol., 2010, 30, 60-72. 